\title{
DISTRIBUCIÓN VERTICAL Y VARIACIÓN ESTACIONAL DEL FITOPLANCTON DE UNA LAGUNA CÁRSTICA MEROMÍCTICA, LA LAGUNA DE LA CRUZ (CUENCA, ESPAÑA)
}

\author{
M.J. Dasí y M.R. Miracle \\ Departament d'Ecologia, Facultat de Ciencies Biologiques, Universitat de Valencia. 46100 Burjassot. España. \\ Palabras clave: phytoplankton, meromixis, Cryptomonas, karstic lakes, Spain
}

\begin{abstract}
VERTICAL DISTRIBUTION AND SEASONAL CHANGE OF PHYTOPLANKTON IN THE KARSTIC MEROMICTIC LAKE LA CRUZ, CUENCA (SPAIN)
\end{abstract}

The vertical distribution of phytoplankton in the iron meromictic, karstic lake of La Cruz (central Spain) was studied during june 1987 to october 1988. Populations were rather stratified.

In the mixolimnion important seasonal variations were observed. In spring Cyclotella glomerata was clearly dominant in the whole profile, accompanied by Pedinomonas minor. Also Rhodomonas lacustris and Peridinium inconspicuum had some relative importance at this time. In early-mid summer these species diminished but remained concentrated in deeper metalimnetic layers. Sunimer was characterized by a bloom of Crucigenia rectangularis which constituted more than the $75 \%$ of the total phytoplankton. Diversity fell to its minimum values and a dramatic precipitation of aragonite took place, which changed the lake water color from green to white. As summer advanced $C$. rectangularis was succeeded by $\mathrm{P}$. minor which had a second and most important peak with relative proportions around $30 \%$ of total phytoplankton. In late summer-autumn these dominance vanished and species, from poorly represented groups before, such as pennate diatoms, crysophytes and dinoflagellates, begin to have some occurrence. Diversity reached its maximum values and phytoplankton density was low. In winter permanent species such as $C$. glomerata and $R$. lacustris had the greater relative abundance but without dominance, coexisting with the still occurring crysophytes and dinoflagellates from autumn.

The phytoplankton of the oxycline constitued a separated community of permanent and constant population throughout the year. This was restricted to this thin layer of water which required adaptations to extrem conditions, low light, temperature and oxygen but which had a rich nutrient supply. The most abundant and typical oxycline species were Cryptomonas obovata, Cryptomonas phaseolus, Astasia curvata and Trachelomonas hispida.

A cluster analysis separated the oxycline species from the rest and grouped the other species according to the their seasonal distribution.

\section{INTRODUCCIÓN}

Recientemente se está prestando gran atención a la vida en condiciones microaerófilas o anaeróbicas. Sin embargo, si bien son frecuentes los trabajos sobre algunos grupos de organismos viviendo en tales condiciones como bacterias fotosintéticas (Guerrero et al., 1985, 1987) y ciliados (FINLAY, 1990; Finlay and FenCHel, 1986) son muy

Limnetica, 7: 37-59 (1991)

(C) Asociación Española de Limnología. Madrid. Spain pocos los estudios existentes sobre algas eucariotas. El presente estudio demuestra la existencia de poblaciones algales relativamente densas en la zona microaerófila de una laguna meromíctica del sistema cárstico de Cuenca, la laguna de la Cruz, mediante la recolección de muestras a intervalos muy pequeños de profundidad en la interfase óxica-anóxica. En esta laguna tiene mucha importancia la compartimentación vertical del agua en epilimnion, hipolimnion y monimolimnion, que conlleva una importante segregación vertical de las comunidades fitoplanctónicas. La caracteriza- 
ción de estas comunidades y su variación estacional, con especial atención a las que se establecen en la interfase óxica-anóxica, cor. tituye el objetivo principal de este trabajo.

La laguna de la Cruz es una torca o dolina llena de agua, formada por la disolución de la caliza en un sistema cárstico de la provincia de Cuenca $\left(39^{\prime \prime} \mathrm{N}, 1^{\circ} 52^{\prime} \mathrm{W}\right)$, a unos $1000 \mathrm{~m}$ sobre el nivel del mar. Concretamente, está situada en la zona de los alrededores de Cañada del Hoyo, a unos $25 \mathrm{~km}$ de la ciudad de Cuenca. Esta laguna tiene una superficie de 1,4 ha, con un diámetro medio de 132 metros y una profundidad máxima de 25 $\mathrm{m}$ en el centro. Presenta una meromixis férrica (Vicente y Miracle, 1988) como resultado de la acumulación de iones solubles, principalmente hierro y bicarbonato, lo cual la convierte en una laguna fuertemente estratificada, con una capa de agua anóxica en el fondo separada del resto por una quimioclina. La composición y características químicas de sus aguas están indicadas en VICENTE y Miracle (1988), tratándose de aguas muy ricas en carbonatos y bicarbonatos pero pobres en otros aniones. Esto se pone de manifiesto cuando todos los veranos, hacia finales de julio, las aguas verde-azuladas del lago toman un color blanco lechoso debido a la precipitación de carbonato cálcico.
La laguna de la Cruz presenta un período de estratificación térmica que comienza en nrimavera y se mantiene hasta otoño y un períodc de mezcla en invierno con oxigenación de las aguas del fondo hasta la quimioclina permanente que se situa a los 18-19,5 m de profundidad (fig. 1), siendo fácilmente detectable debido a los cambios que algunos parámetros físico-químicos experimentan a esa profundidad, en especial la conductividad y el hierro. Durante el período de estratificación, la zona anóxica se encuentra ya a partir de los 12,5-15 $\mathrm{m}$ de profundidad, dependiendo de los anos.

\section{MATERIAL Y MÉTODOS}

Se realizaron un total de 11 campanas de muestreo durante el período comprendido entre junio de 1987 y octubre de 1988, en las que se tomaban muestras en un punto fijo y central de la laguna, a diferentes profundidades dependiendo de la situación de la oxiclina. Por tanto, las profundidades de cada muestreo son distintas y de acuerdo con las condiciones físico-químicas presentes en la laguna. En general se recogían 2 o 3 muestras en

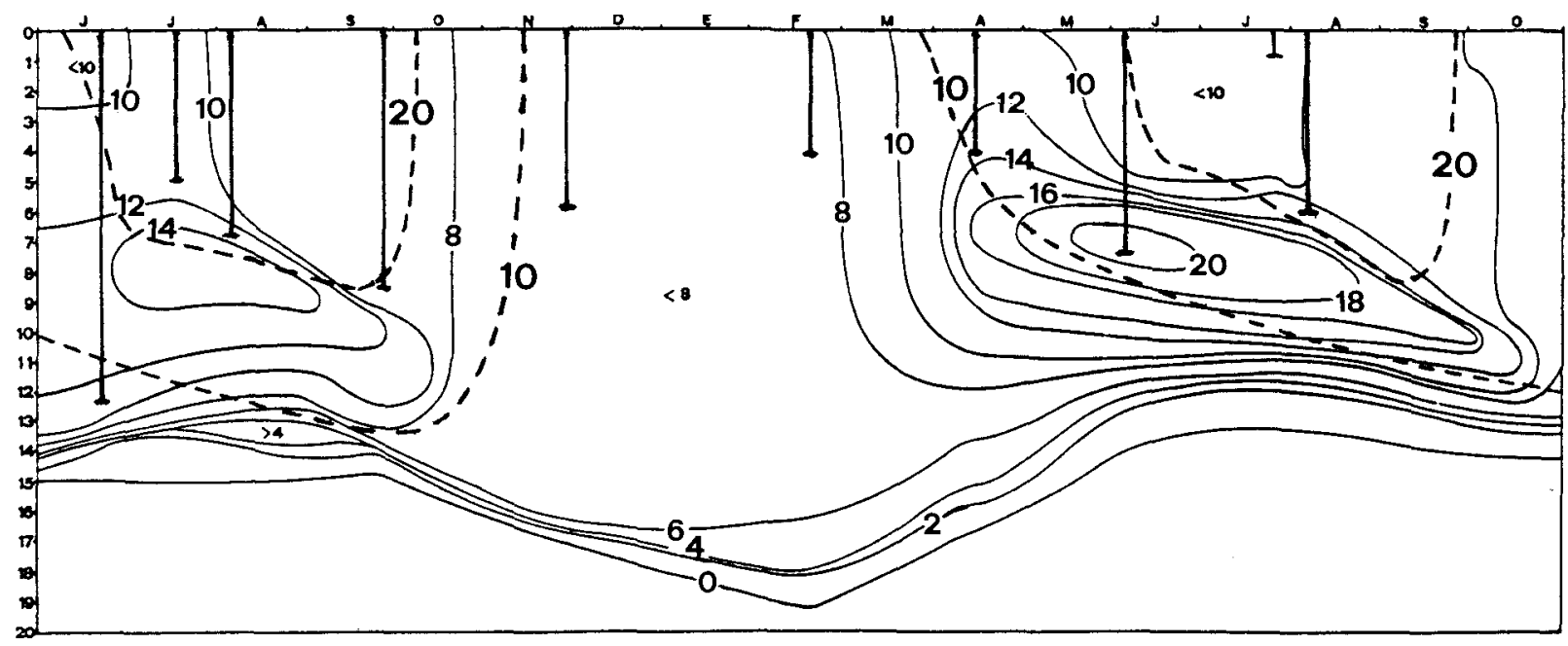

Figura 1. - Isolíneas de la concentración de oxígeno (mgll, líneas continuas) en función de la profundidad (m) y del tiempo, desde junio de 1987 hasta octubre de 1988 . Se han sobrepuesto algunas isotermas $\left(10\right.$ y $20^{\circ} \mathrm{C}$ en líneas de trazos $)$ para situar el epi y metalimnion. Se indica también la profundidad de visión del disco de Secchi.

Oxygen isopleths (mgll, continous lines) according to depth $(\mathrm{m})$ and time, from june 1987 to october 1988. Some isotherms (10 and $20^{\circ} \mathrm{C}$ in dasch lines) have heen superposed to locate epi and metalimnion. Secchi disk depth is also indicated. 
el epilimnion (cerca de la superficie y en la parte más baja), 3 o 4 en el metalimnion y parte aerobia del hipolimnion y un mayor número de muestras en la zona de la oxiclina con intervalos de 20 o incluso $10 \mathrm{~cm}$ sobrepasando el punto de extinción del oxígeno. Las diferentes profundidades de muestreo pueden verse, representadas por puntos, en las figuras de isolíneas (fig. 2 y 3 ).

La temperatura, conductividad y oxígeno fueron medidos in situ con un salinómetro y un oxímetro WTW respectivamente. Las muestras de agua fueron tomadas con una bomba peristáltica conectada a un tubo que terminaba con un muestreador de capa fina (un doble cono de metacrilato cuyas mitades estaban separadas por $1 \mathrm{~cm}$ ).

Las muestras de agua destinadas a estudiar el fitoplancton (177) se recogían en botellas de $500 \mathrm{ml}$ y se fijaban in situ con lugol. Para el recuento del fitoplancton se sedimentaban 50 o $100 \mathrm{ml}$ de muestra, según la densidad de algas, en cubetas de fondo móvil, observándose a $1000 x$ con un microscopio invertido Olympus. Se contaba una media de 200 campos y luego se hacía un rastreo a 400x del fondo de la cubeta, para evaluar la densidad de algas grandes relativamente poco abundantes.

A partir de los datos de ind $/ \mathrm{ml}$ se ha calculado el $n .{ }^{\circ}$ de ind $/ \mathrm{m}^{2}$ para cada especie en la columna de agua entre la superficie y el fondo o entre dos profundidades limitadas por el inicio de fuertes gradientes de temperatura u oxígeno. Para el cálculo del índice de diversidad se ha utilizado el de Shannon-Weaver. Para estudiar las asociaciones entre especies se realizó la matriz de correlación entre ellas, previa transformación logarítmica de los datos originales de individuos por ml. A partir de la matriz de correlación se hizo un análisis de cluster mediante el método Single Linkage (NEAREST NEIGHBOR), introducido a la taxonomía por FloreK et al. (1951a, b) y SNEATH (1957). Tanto la correlación como el análisis de cluster sólo se hizo para las 99 especies más importantes.

\section{RESULTADOS}

\section{Composición específica del fitoplancton}

En la tabla 1 se da una relación de las 133 especies identificadas, ordenadas por su abundancia y grupos taxonómicos, indicándose para las 99 especies más frecuentes: el porcentaje de muestras en que se encontraron, su frecuencia relativa (expresada en tantos por mil respecto del total de individuos del fitoplancton recontados) y su densidad media cuando estaban presentes.

Los gradientes verticales de luz y concentración de nutrientes y oxígeno, así como la distribución de la turbulencia, conducen a la diferenciación de las comunidades por estratos (MARGALEF, 1983). La estratificación de las aguas de la laguna puede representarse con la distribución de la concentración de oxígeno, que muestra un máximo metalimnético y una oxiclina que delimita la interfase óxico-anóxica, tal como puede verse en la figura 1. En esta figura se han representado también las isotermas que delimitan el metalimnion y la profundidad de visión del disco de Secchi. En las figuras 2 y 3 se muestra la distribución de las principales especies en relación con la profundidad y el tiempo durante el período estudiado.

Dada la marcada estratificación que presentan las aguas en esta laguna, se pueden establecer varios grupos de algas atendiendo a su posición en el perfil vertical:

a) Especies del epilirnnion: en este grupo se incluyen aquellas especies que están por encima de la termoclina, y también aquellas especies que a pesar de encontrarse también a otras profundidades, desarrollan grandes poblaciones en el epilimnion.

b) Especies rnetalirnnéticas: se incluyen aquellas especies que se sitúan preferentemente en el metalimnion pero que pueden aparecer también en el epi e hipolimnion. Es el grupo que incluye la mayoría de las especies.

c) Especies meta-hipolimnéticus: incluye a aquellas especies que se desarrollan desde el inicio de la termoclina hasta el inicio de la oxiclina. Entendiendo por oxiclina el gradiente fuerte que lleva a la extinción del oxígeno.

d) Especies de la oxiclina: las especies incluidas aquí, son de dos tipos, aquellas que se encuentran exclusivamente en la oxiclina y a aquellas que viviendo también más arriba en el hipolimnion forman poblaciones mucho mayores en la oxiclina. Las especies que se incluyen en este apartado son aquellas que pueden crecer en condiciones anóxicas o microaerófilas. 
a) Especies del epilimnion

\section{Ceratium hirundinella (O.F. Müller) Schrank}

A esta especie se la suele calificar como una especie de aguas cálidas que se desarrolla preferentemente durante los meses de verano, cuando el agua se halla estratificada térmicamente (Moorr: 1981); es decir, su crecimiento coincide con los momentos en que las aguas son más pobres en nutrientes, sobre todo en las capas superiores. En esta laguna, C. hirundinella presentó siempre pocos individuos por mililitro, contribuyendo poco al número total de células de fitoplancton, alcanzando la máxima abundancia de todo el período estudiado en septiembre de 1987, eri la parte superior de la termoclina (que se hace profunda en esta época del ano). a $10,5 \mathrm{~m}$ de profundidad con 41,29 indiml.

\section{Nuviculu cf. cryptocephala Kütz.}

Los especímenes encontrados en esta laguna tienen un tamaño de alrededor de $22 \mu$ de largo y 5,7-6,42 $\mu$ de ancho, ligeramente inferior al hasta ahora descrito para esta especie (25-35 $\mu)$ pero coincidiendo, sin embargo, en el resto de características. siendo por ello por lo que se ha aproximado a $N$. cryptocephalu. Ha aparecido más abundantemente en los meses de finales de verano, en las capas de agua superiores a la termoclina. Presentó un crecimiento explosivo a principios de octubre de 1988, localizado a los $5 \mathrm{~m}$ de profundidad (con densidades de $1000 \mathrm{ind} / \mathrm{ml}$ ), acompañado por picos de población de otras diatomeas pennadas del género Nitzschia.
Nitzschia palea var debilis (Kütz.) Grun.

Esta variedad es de menor tamaño que Nitzschia palea, con un tamaño de $20.33 \mu$ de largo por $3,21 \mu$ de ancho. Se trata de un alga muy poco frecuente en la laguna pero a principios del mes de octubre de 1988 tuvo un importante crecimiento localizado a $5 \mathrm{~m}$, junto con otra especie de Nitzschia y la Navicula antedicha, con unos $300 \mathrm{ind} / \mathrm{ml}$, mientras que apenas apareció en las restantes profundidades.

\section{Planctonema lauterbornii Schmidle}

Es una clorofícea ulotrical cuyos filamentos son cortos y flotan libremente. Las células que forman sus tricomas son cilíndricas y redondeadas en los extremos y tienen una longitud aproximada de 10 $\mu$, siendo la anchura del filamento de $3 p$. Presenta mayor crecimiento en las capas de agua superficiales, concretamente desde la superficie hasta los $5 \mathrm{~m}$ aproximadamente, aunque también se ha encontrado en las últimas capas del metalimnion. En cuanto a su distribución a lo largo del año, presenta mayor número de filamentos por mililitro durante los meses de verano, apareciendo regularmente desde julio hasta octubre de 1988, mientras que en el año anterior su crecimiento se retrasó hasta septiembre. Por tanto, al igual que en los embalses de Cúber y Gorg Blau (Mallorca, Ramon y Moya 1984) y en el lago de Estanya (Huesca, Avila et al. 1984), el período de mayor desarrollo de esta especie algal se da a finales de verano. De hecho, el máximo detectado fue de 250 filamentos/ml el 30 de septiembre de 1988.

Tabla 1 (página siguiente). - Relación de las especies del fitoplancton de la laguna de la Cruz indicando su porcentaje de presencia en las muestras (1), su frecuencia (\%) respecto del número total de individuos contado (336 x 10") (2) y su densidad media cuando estaba presente, en individuos $/ \mathrm{ml}$ (3). ${ }^{*}$ indica frecuencias relativas menores de un $0.1 \%$.

Phytoplankton species from Laguna de la Cruz indicating their percentatge of occurrencc (relative to the total number of samples) (1), their frecuency (\%o) relative to the total number of individuals counted $\left(436 \times 10^{6}\right)(2)$ and their mean density when where present (in individuals $/ \mathrm{ml}$ ) (3). * indicates relative frequencies less than $0.1 \%$. 


\begin{tabular}{|c|c|c|c|c|c|c|c|}
\hline & (I) & (2) & (3) & & (I) & (2) & (3) \\
\hline Dinophyceat & & & & Cyanophyceac & & & \\
\hline Peridiniam palatinum & 67,2 & 5,7 & 20,9 & Anabaena sp. & 14,7 & 1.6 & 10,7 \\
\hline Peridinumon inconspicutum & 72.9 & 20,5 & 69,2 & Spirulina major & 1.7 & * & 1.9 \\
\hline Pridiniam striolatum & 12,4 & 0.7 & 13.2 & Lyngbya perelegans & 2.3 & * & 1.9 \\
\hline Peridinium volzil & 44.6 & 1.7 & 9,6 & Pseudanabaena limnetica & 16,9 & 0,3 & 4,3 \\
\hline Peridinium cinclum & $x, 5$ & 0.2 & 5.5 & Pseadanabaena catenata & 3,4 & * & 2,1 \\
\hline Peridiniam bipes & 3,4 & x & 3.8 & Oscillatoria of. amphigranulata & 3.9 & * & 3.9 \\
\hline Peridinium gonlavionse tat), remontum & 2.3 & × & 4.5 & Oscillatoria tenuis & 1,7 & * & 1.7 \\
\hline Peridinium gulwinskii & 1,7 & + & 9.2 & Microcystis aeruginosa var. major & 5.6 & 0.6 & 24.9 \\
\hline Peridiniam umbonatum & 2,3 & 11.1 & 14.8 & & & & \\
\hline Peridinium cinctum f. owoplanum & 1.1 & $*$ & 16,5 & ( hlorophyla & & & \\
\hline Gymnodinium varians & 21,5 & 2.4 & 27.7 & (osmarium punculatum & 14.1 & 0,2 & 2.6 \\
\hline Gymnodinium of bogoriense & 41,8 & 3,4 & 19,8 & Cosmarum botrutis & 0,6 & $*$ & 2.5 \\
\hline Gymnodinium of. rotundatum & 8.5 & 0,7 & 21.5 & Cosmarum abbreviatum $\mathrm{i}$ ar abbreviaum & 3,4 & * & 2.4 \\
\hline \multirow[t]{3}{*}{ Ceratium hirundinella } & 24,9 & 0,6 & 6.2 & Cosmarnm regulare & 1,7 & 0,3 & 42.9 \\
\hline & & & & Cosmarum laeve & 1,1 & * & 5.9 \\
\hline & & & & Cosmarum reniforme & 2,3 & * & 0.6 \\
\hline Cryptophyceae & & & & (osmarum bionalatum $\mathrm{t}$ ar bioculatum & 0,6 & * & 0.6 \\
\hline Cryptomonas erosa & 95.5 & 54,4 & 140,0 & Cosmartum tenustum & 1.7 & * & 3.9 \\
\hline Cryptomonas obovala & 76,8 & 74.5 & 239,0 & Cosmarum angulosum & 0.6 & * & 3.0 \\
\hline Cryptomonas phaseolus & 62,7 & 42.8 & 168,0 & Closterium gracile & 0,6 & * & 0,6 \\
\hline \multirow[t]{3}{*}{ Rhodomonas lacustris } & 80.2 & 77.6 & 238.0 & Closterium parnulum tar parnulum & 1.1 & $*$ & 2.6 \\
\hline & & & & (Iosterium sp. & 1.7 & * & 2,8 \\
\hline & & & & Roya cambrica & 9,6 & * & 2.2 \\
\hline Bacillariophyceat & & & & Monoraphidium menutum & 80.2 & 26.8 & 82,2 \\
\hline Cyclotella glomerata & 80,8 & 133.6 & 404,0 & Monoraphidium tortile & 59,9 & 3,5 & 14,2 \\
\hline Cyclotella kützingiana & 21,5 & 6,8 & 78,5 & Monoraphidium irregulare & 19.2 & 0.6 & 7.6 \\
\hline Stephanodiscus dubius & 1,1 & * & 1,3 & Monoraphidium convolutum & 8,5 & 1.9 & 55,8 \\
\hline Navicula cf. cryptocephala & 14,1 & 2.8 & 48.0 & Monoraphidium komarkovae & 8,5 & 0,4 & 11,8 \\
\hline Navicula radiosa & 11,3 & 0,2 & 3.8 & Monoraphidium contortum & 4,5 & 0,6 & 30,9 \\
\hline Navicula bacilloides & 2,3 & * & 2,2 & Tetraedron mumum & 12.4 & 0,3 & 6,5 \\
\hline Navicula lanceolata & 1.7 & & 0.5 & Tetraedron $s p$ & 2,3 & $*$ & 5.9 \\
\hline Navicula sp. & 0,6 & & 13,8 & Pedinomonas minor & 63,8 & 111,0 & 428.0 \\
\hline Nitzschia palea & 19,8 & 0,7 & 8,3 & Oocystis sp. & 74,0 & 6,6 & 22,0 \\
\hline Nitzschia palea var. debilis & 1,1 & 0,7 & 148,0 & Scenedesmus linearis & 40,7 & 6,2 & 37.7 \\
\hline Nirzschia gracilis & 38.4 & 1.0 & 6,6 & Scenedesmus ecornts & 27,7 & 1.6 & 13,8 \\
\hline Nitzschia microcephala & 0,6 & $*$ & 2,1 & Scenedesmus quadricauda & 21.5 & 1,1 & 12.9 \\
\hline \multirow[t]{3}{*}{ Nitzschia $S D$} & 1.1 & 0.6 & 128.0 & Scenedesmus serratus & 31,6 & 1.2 & 17.2 \\
\hline & & & & Scenedesmus denticulatus & 8,5 & 0,2 & 4.6 \\
\hline & & & & Scenedesmus acummatus & 0,6 & * & 13,8 \\
\hline Chrysophyceac & & & & Scenedesmus longispina & 3.4 & $*$ & 3,5 \\
\hline Dinobryon sp. & 1,1 & $*$ & 7,8 & Scenedesmun lefevrii & 22.0 & 0,8 & 8.4 \\
\hline Chrysolykos planctonicus & 16,9 & 10.8 & 157,0 & Scenedesmus nanus & 1,1 & $*$ & 12,9 \\
\hline Calycomonas sp. & 11.3 & 3,4 & 73,1 & Scenedesmus quadrispina & 2,3 & $*$ & 4,3 \\
\hline Kephyrion sp. & 18.1 & 2,1 & 28,9 & Scenedesmus circumfusus & 1,7 & * & 6,8 \\
\hline Diceras ollula & 6,2 & 0,3 & 9,8 & Scenedesmus cf. granulatus & 0,6 & * & 2,3 \\
\hline Diceras cf. chodati & 1,1 & $*$ & 10,9 & Scenedesmus acutus & 0,6 & * & 24,2 \\
\hline \multirow[t]{3}{*}{ Chromulina sp. } & 29,9 & 16.9 & 139,0 & Chlorella sp. & 45.2 & 12,5 & 67,9 \\
\hline & & & & Crucigenia rectangularis & 61,0 & 269.0 & 109,0 \\
\hline & & & & Pseudoquadrigula sp. & 28,3 & 6,1 & 53,5 \\
\hline Euglenophyceac & & & & Ankistrodesmus $s p$ & 24,3 & 0.8 & 8.4 \\
\hline Astasia curvutu & 30,5 & 5,7 & 46,0 & Keratococcus mucicola & 10.2 & 2,4 & 57.7 \\
\hline Astasia cf. oblonga & 28.3 & 10.3 & 89,7 & Planctonema lauterbormi & 30,5 & 4.6 & 36,8 \\
\hline Astasia inflata & 6,2 & 0.6 & 22,0 & Pediastrum boryanum & 13,6 & 0.2 & 3,7 \\
\hline Euglena acus & 18,1 & 0.3 & 3,9 & Chlamydomonas acuta & 6.2 & 8,3 & 330,0 \\
\hline Trachelomonas hispida & 61,0 & 2,8 & 11,2 & Chlamydomonas passiva & 25.9 & 5.6 & 53,1 \\
\hline Trachelomonas intermedia & 4.5 & 0.2 & 10.6 & Chlamydomonas of gloeophila & 35.6 & 4.5 & 31,1 \\
\hline
\end{tabular}


b) Especies metalimnéticas

Peridinium palatinum Lauterboin 1896

Dinoflagelado frecuente en el fitoplancton de la laguna de la Cruz, apareciendo en todos los muestreos realizados. Su tamaño es de 38-40 $\mu$ de longitud y de 35-36 $\mu$ de anchura. En cuanto a su distribución a lo largo del período estudiado, presentó un máximo de 147 indlml en septiembre de 1987 a 11,5 m, no disminuyendo mucho su crecimiento durante los meses de invierno, detectándose en febrero una importante cantidad de células. Su distribución en la columna de agua varía de unas estaciones a otras, así en los meses en los que la laguna está estratificada aparece hasta los 14-15 m de profundidad aproximadamente, a excepción del muestreo del mes de julio de 1988, coincidente con la precipitación de carbonato cálcico, y en el que Peridinium palatinum, debido a la gran turbidez del agua y a la escasa penetración de la luz, sólo se encontró hasta los $10 \mathrm{~m}$. En el mes de agosto (tanto de 1987 como de 1988), es cuando más se concentró su población, encontrándose sólo desde los 10 hasta los $15 \mathrm{~m}$ en ambos casos. En los meses de mezcla, se detectó también hasta la profundidad de la oxiclina.

\section{Peridinium inconspicuum Lemmerman 1899}

Esta especie es la que alcanzó mayor desarrollo de todos los Peridinium, siendo la más frecuente y también la más abundante en esta laguna. Es de menor tamano que $\mathrm{P}$. palatinum, con una longitud de 20 a 23 y y con una anchura de 15 a 22 y. Aparece desde la superficie hasta una profundidad que varió según la época del ano, al igual que ocurría con $P$. palutinum. Durante la época de mezcla se encontró hasta $17 \mathrm{~m}$. Durante los meses en que la laguna estuvo estratificada llegó hasta los 12 y los $15 \mathrm{~m}$ de profundidad, según la posición de la oxiclina. En el verano de $1987 \mathrm{su}$ crecimiento se vio retardado respecto al de 1988 , apareciendo en poca cantidad en junio y julio, para alcanzar ya gran densidad en agosto y sobre todo en septiembre, mientras que en 1988 su desarrollo empieza mucho antes, alcanzando ya los 544 indlml en el mes de abril.

\section{Peridinium volzii Lemmerman 1905}

Es el Peridinium de mayor tamano aparecido en la laguna, con una longitud de $42-48$ y y una anchura de 43-48 y, es decir, tiene una forma casi totalmente esférica. Esta especie apareció en todos los meses de muestreo menos er noviembre y febrero de 1987 y 1988 respectivamente. A pesar de ser bastante frecuente su población nunca alcanzó grandes concentraciones de organismos, sierido el máximo de 142 indlml en agosto de 1987 a $14 \mathrm{~m}$ de profundidad. La profundidad máxima a la que se encontró en todo el período estudiado fue de $15 \mathrm{~m}$ (en junio de 1987).

\section{Rhodomonas lacustris Pascher \& Ruttner}

El tamano de esta alga en la laguna de la Cruz es de $5 \mu$ de anchura por $10 \mu$ de longitud. Apareció en todos los muestreos realizados pero su crecimiento fue mayor en los meses de verano, alcanzando más de 1000 indlml en agosto del 87 y julio del 88. La precipitación de carbonato cálcico también afectó su distribución, pasando de una profundidad máxima de $14 \mathrm{~m}$ el día 25 de julio a $12 \mathrm{~m}$ el día 27. Al mes siguiente, agosto de 1988, una vez la laguna ya había vuelto a la normalidad, volvió otra vez a situarse alrededor de los 13-14 m como profundidad máxima.

\section{Cyclotella glomeratu Bachmann}

Ésta ha sido la diatomea más abundante y frecuente en la laguna. Su tamano fue de 6-7 y de diámetro. Presenta estrias periféricas muy delicadas, estando el centro desprovisto generalmente de ornamentos. Alcanzó sus poblaciones más importantes, en cuanto a número de individuos, en el mes de junio, tanto de 1987 como de 1988, llegando a contarse en junio de 1987 más de 3800 indlml. En verano sus poblaciones están más localizadas, presentando máximos metalimnéticos profundos.

\section{Cyclotella kützingianu Thwaites}

Sus valvas son cilíndricas y presentan también estrías en la periferia. Su diámetro es mayor que el de Cyclotella glomeratu, con una variación entre 10 y 20,3 y. Se cita como especie limitada a los medios calcáreos. Fué mucho menos frecuente que la anterior. Apareció desde los 10 hasta los $13 \mathrm{~m}$ de profundidad en los meses de verano, sin embargo en la época de mezcla está más dispersa.

\section{Monoraphidium minutum (N.) Kom.-Legn.}

Se trata de una clorofícea de pequeño tamaño, 1,6 $\mu$ de ancho por 6-7 de largo. Esta especie es 
muy frecuente en esta laguna, apareciendo en todos los muestreos realizados y alcanzando en algunas ocasiones un gran desarrollo, sobre todo en los meses de julio (con una densidad máxima de 720 indiml) y agosto.

\section{Scenedesmus linearis Kom.}

Es una clorofícea bastante frecuente en esta laguna. El tamaño de cada célula es de 13-15 $\mu$ de largo por 3 y de ancho. Al igual que Monoraphidium minutum, esta alga aparece fundamentalmente en el metalimnion aunque crece también abundantemente en el epilimnion. Su máximo desarrollo lo alcanzó en octubre de 1988 a 5 m con 183 indiml. Su crecimiento se ve bastante reducido durante el invierno.

\section{Crucigenia rectangularis (Näg.) Gay. 1891}

Es una clorofícea que constituye una parte muy importante del fitoplancton de esta laguna, pues es muy frecuente y además alcanza un gran desarrollo en los meses de verano. Las células aparecen siempre agrupadas de cuatro en cuatro, constituyendo cenobios. Las células son más o menos aplanadas y de forma elipsoidal. Los cenobios son rectangulares y pueden ser compuestos, de hecho, en esta laguna lo son la mayoría de las veces. Sus mayores poblaciones se dieron en julio de 1987 con densidades superiores a los 5000 ind $/ \mathrm{ml}$. Durante los meses de invierno y primavera de 1988 desapareció por completo, pero volvió a aparecer en junio, alcanzando ya cantidades importantes en julio. Después del verano, volvió a disminuir. En 1988 se mantuvo todavía con más de $1000 \mathrm{ind} / \mathrm{ml}$ en la termoclina profunda de finales de septiembre.

\section{Pediastrum boryanum (Turp.) Meneg.}

Se trata de una especie cuyas células aparecen agrupadas formando colonias. El número de células que forman la colonia puede ser de hasta 128 (StKeble \& Krauter, 1987) pero no es éste el caso en esta laguna, donde la media es de unas 16 células por colonia. Las células marginales de la colonia se prolongan en lóbulos agudos. La distribución de esta diatomea en la laguna de la Cruz es bastante clara, desarrollándose en los meses de verano y situándose más abundantemente alrededor de la termoclina, siempre con densidades muy bajas.

\section{Pedinomonas minor Korsch.}

Se trata de una clorofícea de pequeño tamaño (4 $\mu$ de ancha y 4.5 u de larga) cuyas células son asimétricas y sin pared celular. Presentan un flagelo y en la base de éste hay una vacuola contráctil. Es muy frecuente en el plancton de esta laguna, estando presente en ella todo el tiempo que comprende este estudio y alcanzando en algunas ocasiones enorrnes cantidades de células por unidad de volumen. Así, en septiembre de 1987 y en octubre de 1988, se contaron más de 5000 indiml. En abril de 1988 también fue muy importante su presencia desde el punto de vista cuantitativo. Por tanto, parece que esta especie crece muy bien desde la segunda mitad del verano hasta principio de otoño y también en primavera. Apareció en todas las profundidades estudiadas los meses de mezcla y desde la superficie hasta una profundidad que varió entre 12 y $15 \mathrm{~m}$ durante los meses de estratificación.

\section{c) Especies meta-hipolimnéticas}

\section{Nitzschiu palea (Kütz.) W. Smith}

Se trata de una diatomea pennada de 34 y de largo y $5 \mu$ de ancho, que presenta en la superficie del frústulo unas estrías muy finas. Se encuentra en aguas bastante contaminadas, siendo parcialmente heterótrofa. En la laguna de la Cruz tiende a situarse en profundidades donde el oxígeno es escaso pero casi siempre por arriba de la oxiclina, aunque no tiene una distribución del

Figura 2 (páginas siguientes). - Distribución de la densidad de población (indlml) de las principales especies del fitoplancton en función de la profundidad (m) y del tiempo, desde junio de 1987 hasta octubre de 1988. Las isolíneas se han interpolado libremente entre las muestras. indicadas por puntos.

Depth (m, ordinates) and temporal (months from june 1987 to october 1988) distribution of population density (indiml) of the main phytoplankton species. Isoplcths have becn freely interpolated between the samples indicated by dots 

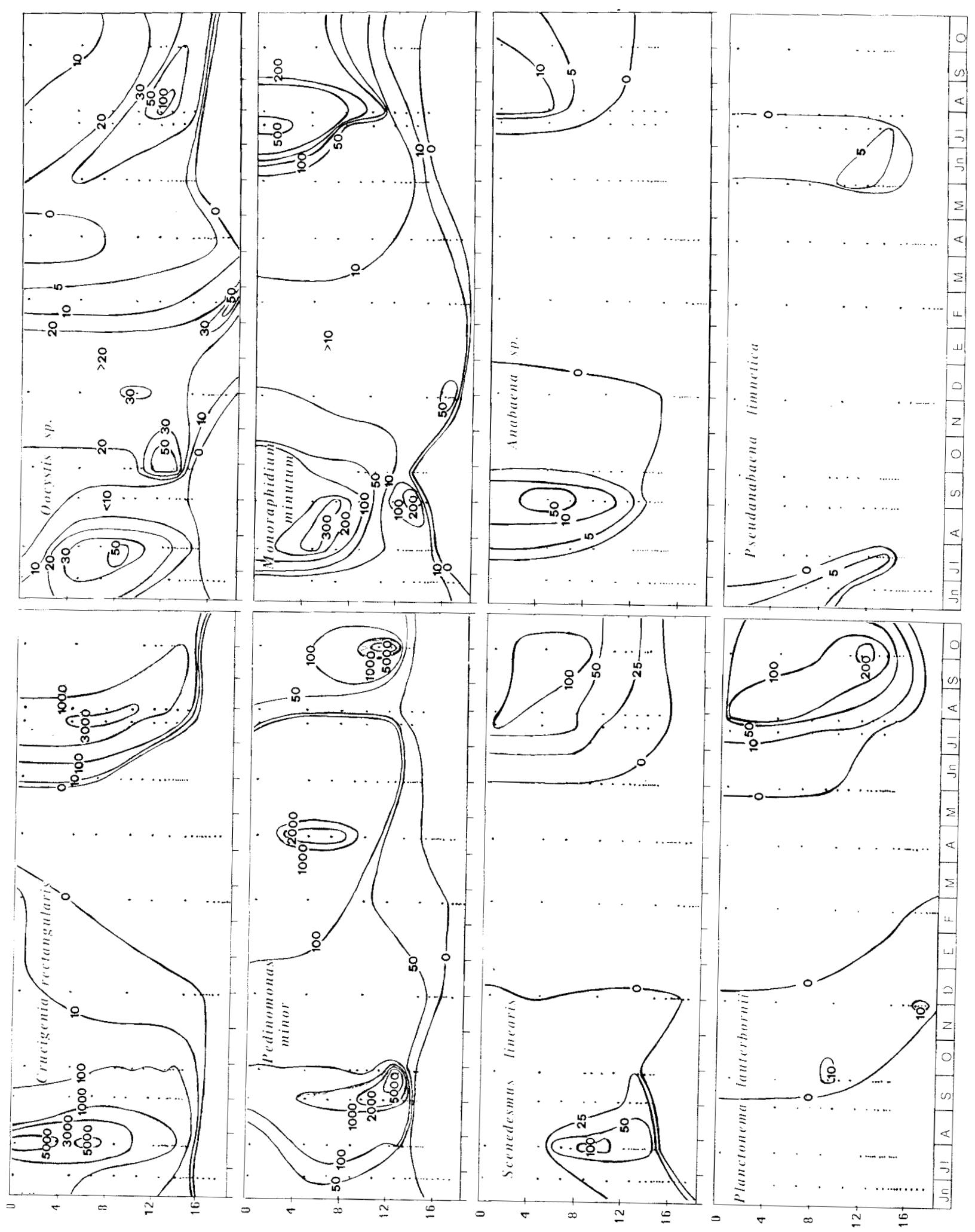


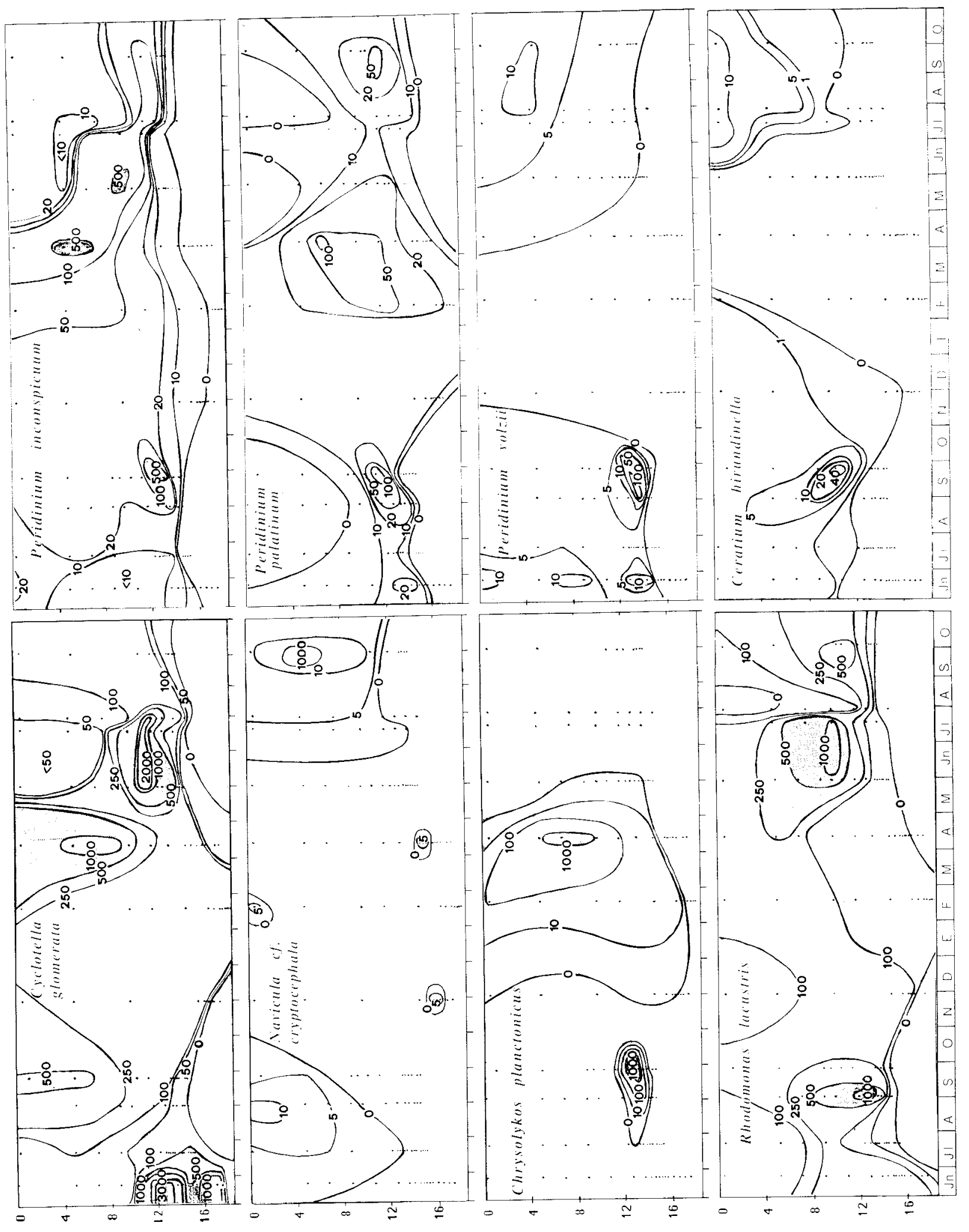


todo clara. No alcanzó cantidades importantes de individuos por volumen pero fue la Nitzschia que apareció con mayor regularidad.

\section{Chrysolykos planctonicus Mack 1951}

Son células solitarias planctónicas libres y tienen una Ióriga hialina en forma de croissant muy curvado con un divertículo en operón opuesto a la abertura. La longitud de esta Ióriga es de 16 y, mientras que la anchura resulta difícil de medir debido a su peculiar forma. Su crecimiento se da a partir de los $13 \mathrm{~m}$ aproximadamente en los meses de estratificación, mientras que aparece en todo el perfil vertical los meses de mezcla, así en febrero se encontró desde 0,5 hasta los 17,5 m. Los meses en los que presentó mayor desarrollo fueron septiembre de 1987, con 1242 indlml a $13,5 \mathrm{~m}$ de profundidad, y en abril de 1988, con 936 indlml.

\section{d) Especies de la oxiclina}

\section{Cryptomonus erosa Ehrenberg}

Se trata, al igual que el resto de Cryptomonas, de células libres. El tamano de esta alga en la Laguna de la Cruz varió entre 19,5-21 y la longitud y entre 8-11 la anchura. Tanto esta especie, como el resto de especies de este mismo género encontradas en la laguna presentan bastante variabilidad en el tamano. Morgan \& KalfF (1975) encontraron $C$. erosa a muy bajas temperaturas y bajas intensidades de luz y observaron que la célula acumulaba en su interior gránulos de almidón y presentaba mayor tamaño, considerándolo como una adaptación a la supervivencia en condiciones de oscuridad debajo del hielo. C. erosa apareció en todos los muestreos realizados, es decir, en todas las estaciones, alcanzando gran desarrollo en los meses más cálidos, no por ello dejando de ser importante parte del fitoplancton total en los meses de invierno, con cantidades incluso de más de $1000 \mathrm{ind} / \mathrm{ml}$ a algunas profundidades. En julio de 1987 alcảnzó más de 2500 indlml a 15,5 m de profundidad. En cuanto a su distribución a lo largo de la columna de agua, Cryptomonas erosa crece a casi todas las profundidades, pero se ha encontrado mayor número de individuos a partir de los $14 \mathrm{~m}$ aproximadamente, con un máximo en el perfil vertical alrededor de los $15 \mathrm{~m}$ en los meses de estratificación. Esta alga se presenta mucho más dispersa en la columna de agua durante los meses de invierno.

\section{Cryptomonas obovata Skuja}

Esta especie es de gran tamano, el cual varía bastante de unos individuos a otros, oscilando entre 16,2 y $24 \mu$ de anchura y de 29,16 a 41,5 y de longitud. En muestras vivas se ha podido observar que se desplaza muy rápidamente en el medio, teniendo, como consecuencia, fácil acceso a los nutrientes. También apareció en todos los muestreos, pero a diferencia de Cryptomonas erosa sólo se encontró en toda la columna de agua en los meses de invierno (desde noviembre hasta febrero), empezando a encontrarse desde los $5 \mathrm{~m}$ en el mes de abril, desde los 7,7 m en julio y desde los $12 \mathrm{~m}$ en agosto de 1988. En todos estos casos el alga se detectó hasta la mayor profundidad muestreada, llegando a encontrarse por debajo de la oxiclina, alcanzando incluso allí importantes poblaciones. Así, en agosto de 1987 y a $14,7 \mathrm{~m}$ de profundidad alcanzó su máxima densidad, con más de $3800 \mathrm{ind} / \mathrm{ml}$, encontrándose la extinción de oxígeno ese mes a los $14,9 \mathrm{~m}$.

\section{Cryptomonas phaseolus Skuja}

Es la especie de Cryptomonas de menor tamaño encontrada en esta laguna, no presentando tanta variabilidad de tamano como la anterior, con un tamano de $7-8 \mu$ de anchura y $12-13$ y de longitud. Presenta un comportamiento parecido a Cryptomonas obovata, situándose incluso por debajo de ésta, es decir, tiende a situarse en la oxiclina y en las capas más profundas del hipolim-

Figura 3. - Distribución de la densidad de población (ind./ml) de las especies del fitoplacton que se situan en la oxiclina, según la profundidad y el tiempo, tal como se indica en la figura 2.

Depth (m. ordinates) and time (months from June 1987 to October 1988) distribution of population density (ind./ml) of the phytoplarictoriic spccics which arc located in the oxycline. Isopleths as in figurc 2. 


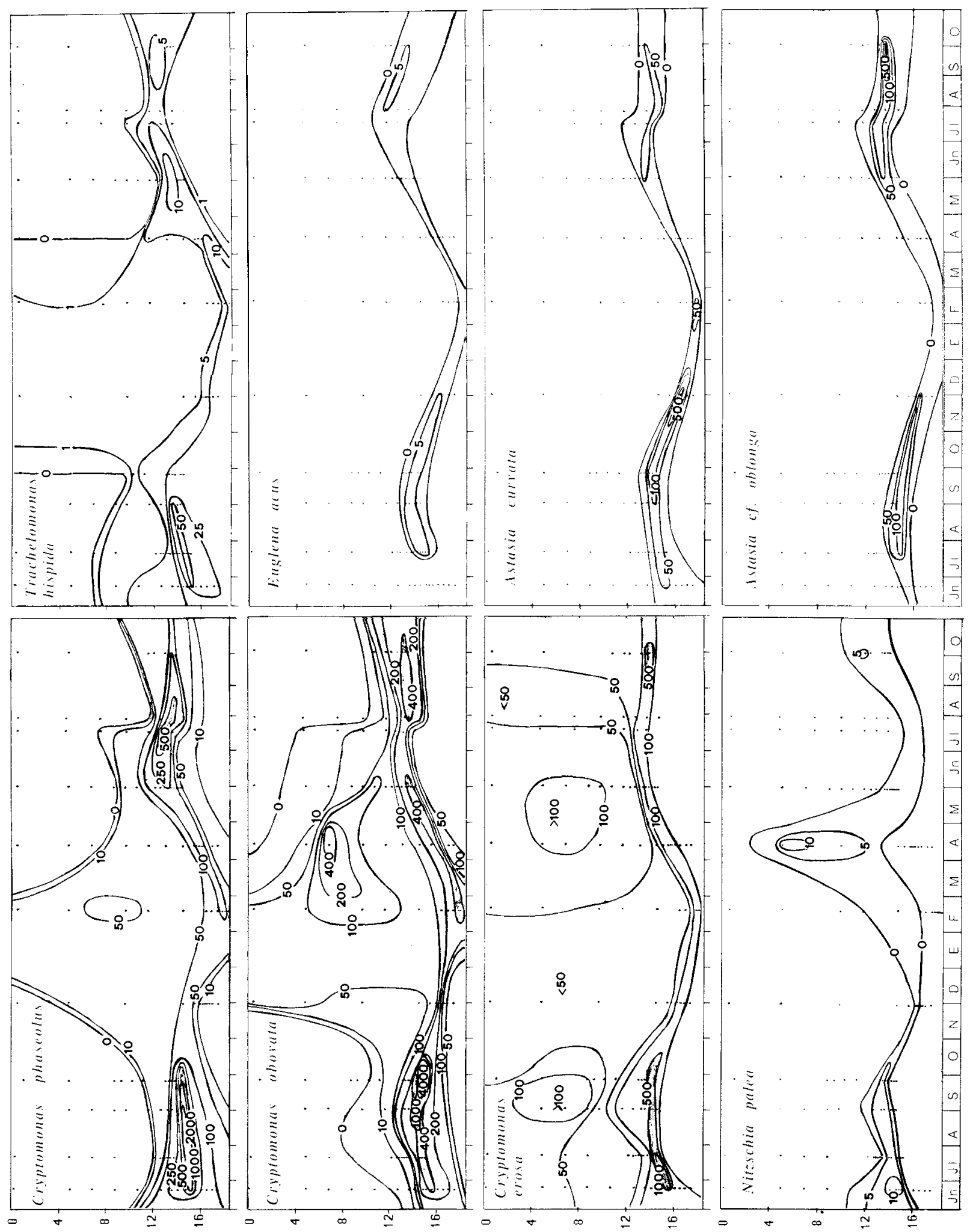


nion. Su mayor desarrollo lo alcanzó en julio de 1987 a $15,4 \mathrm{~m}$ de profundidad, con más de 2000 indlml. Se ha citado como característica de la interfase óxico-anóxica en prácticamente todos los lagos españoles que la presentan, tanto cársticos (la laguna del Sisó, Pedros-Alıó et al., 1987; la laguna del Vilá, García 1973; el lago de Estanya, Avila et al., 1984) como del litoral marino (l'Estany de Cullera, Rojo y Miracle 1989).

\section{Astasia curvata Klebs}

Alga euglenofita de forma curvada, estrecha y que no presenta cloroplastos. Su tamano es de unas $5 \mu$ de ancho por 46,2 y de largo. Esta especie es la más abundante de este género en la laguna. Así, estuvo presente en la laguna en todos los meses muestreados, pero en el año 1987 tuvo mayor desarrollo que en 1988, alcanzando en noviembre del 87 casi 700 indlml. Es exclusiva de la oxiclina, apareciendo normalmente alrededor de los 14-15 m de profundidad y hasta una profundidad de 18-19 m.

\section{Astasia cf. oblonga Skv.}

Esta alga es de menor tamano que Astasia cur$v a t a$, teniendo una longitud de $17 \mu$ y una anchura de $7 \mathrm{y},(1 \mathrm{y}$ menos, tanto en longitud como en anchura del intervalo de tamaños que se cita en la literatura para A. oblonga). Su distribución es muy similar a la de $A$. curvata, tanto en profundidad como a lo largo del año, alcanzando su máximo de indlml en octubre de 1988 a 14 metros de profundidad con 534,86 .

\section{Euglena acus Ehrenb.}

Esta especie la constituyen células fusiformes largas con un flagelo ( $92 \mu$ de longitud y $9.72 \mu$ de anchura), cloroplastos en forma de placas y con movimientos lentos debido a que es bastante rígida. Se suele encontrar en aguas ricas en substancias nutricias, encontrándose en esta laguna exclusivamente en las capas de agua de la oxiclina. Aunque estuvo presente en muchas ocasiones en la laguna, el número de células encontradas era siempre escaso, con un máximo en julio de 1987 a 14.6 metros de 18 indlml.

\section{Trachelomonas hispida (Per.) Stein.}

Células que presentan caparazón de contorno ovalado, revestido con cortas espinas densamente y regularmente dispuestas. El tamano que presentó en esta laguna ha sido de $32 \mu$ de longitud y $23 \mu$ de anchura. En los meses de verano parece que se encuentra ligeramente en mayores cantidades que en los meses de invierno, alcanzando su máximo desarrollo en agosto de 1987, con 62 indlml. Apareció normalmente a partir de los 9-11 m, aunque en junio de 1988 no lo hizo hasta los $13,4 \mathrm{~m}$, alcanzando una profundidad de $19 \mathrm{~m}$ en febrero de 1988, único mes donde se muestreó hasta los $19 \mathrm{~m}$.

Scenedesmus quadricauda (Turp.) Bréb.

Esta especie se encontró formando colonias de 4 células normalmente. Sus células tienen una anchura de 4 y y una longitud de 10 p. Las células terminales presentan dos espinas dirigidas hacia el exterior y curvadas hacia arriba. Se localiza en el hipolimnion y alcanza también la oxiclina, apareciendo en mayores cantidades a partir de los 12,5-13 m de profundidad. Durante los meses de mezcla, el alga se encontró desde la superficie hasta los 18-18,5 m, mientras que el resto de meses se presentó exclusivamente en la oxiclina.

\section{Scenedesmus serratus (Corda) Bohl.}

El tamano de las células es de 11-12 $\mu$ de longitud y unas $4 \mu$ de anchura. Al igual que Scenedesmus quadricauda, tiende a situarse cercana a la oxiclina. En febrero de 1988 llegó a presentar a $18,7 \mathrm{~m}$ más de 100 indlml. En cuanto a su distribución a lo largo del año no parece que varíe mucho, salvo su presencia en todo el perfil vertical los meses de mezcla, cosa muy normal para otras muchas algas.

\section{Sucesión estacional}

En la figura 4 se representan en histogramas el total de individuos $/ \mathrm{m}^{2}$ de cada grupo junto con la especie más abundante del mismo, responsable básico de su variación estaciona].

De los grupos de algas que forman el fitoplancton de la Laguna de la Cruz, es el de los clorófitos el representado por mayor número de especies. La elevada proporción de los clorófitos respecto del número total de individuos del fitoplancton se debe sobre todo al crecimiento masivo que experimentan unas pocas especies, concretamente Crucigenia rectangularis, Pedinomonas minor y 
también Monoraphidium minutum aunque en menor proporción. Los clorófitos presentan un porcentaje elevado en los meses de verano, en concreto desde julio hasta septiembre u octubre, con un máximo en julio y agosto (89 \% del fitoplancton total en julio de 1987). La mayor aportación a estos máximos fue la de Crucigenia rectangularis, cuya proporción relativa respecto del total del fitoplancton fue del $75 \%$ en julio de 1987 y del $63 \%$ en julio y principios de agosto de 1988. Más
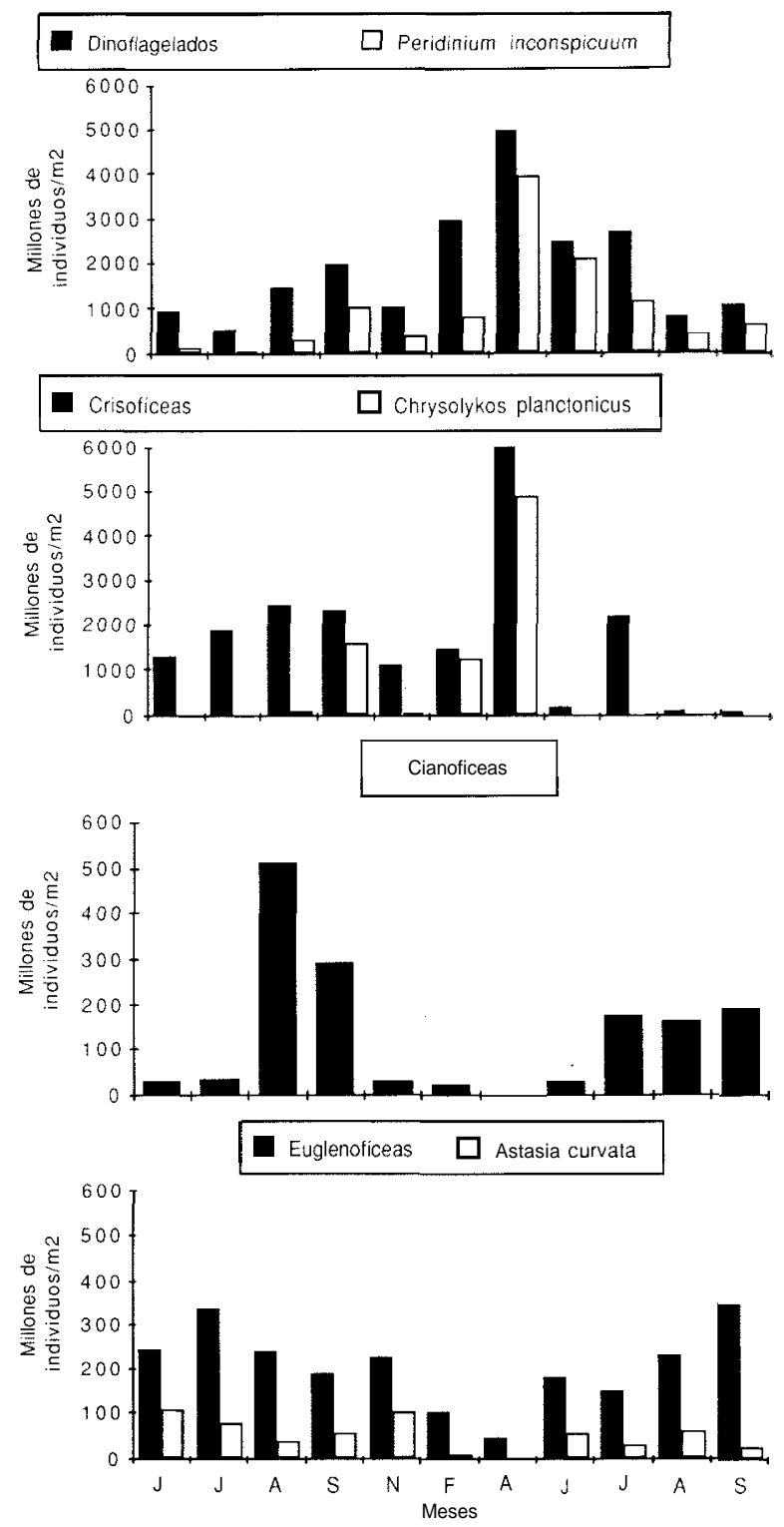

avanzado el verano, la composición fitoplanctónica cambia a favor de Pedinomonas minor, con altas proporciones relativas respecto del total del fitoplancton por columna de agua $(38 \%$ a finales de agosto en 1987, $39 \%$ a finales de septiembre en 1988), quedando Crucigenia rectangularis muy relegada (con un $5 \%$ en septiembre de 1987 y un $15 \%$ en septiembre de 1988). Otros clorofitos importantes en estas épocas fueron Monoraphidium minutum (con proporciones del 2 al 7 \%). De apa-
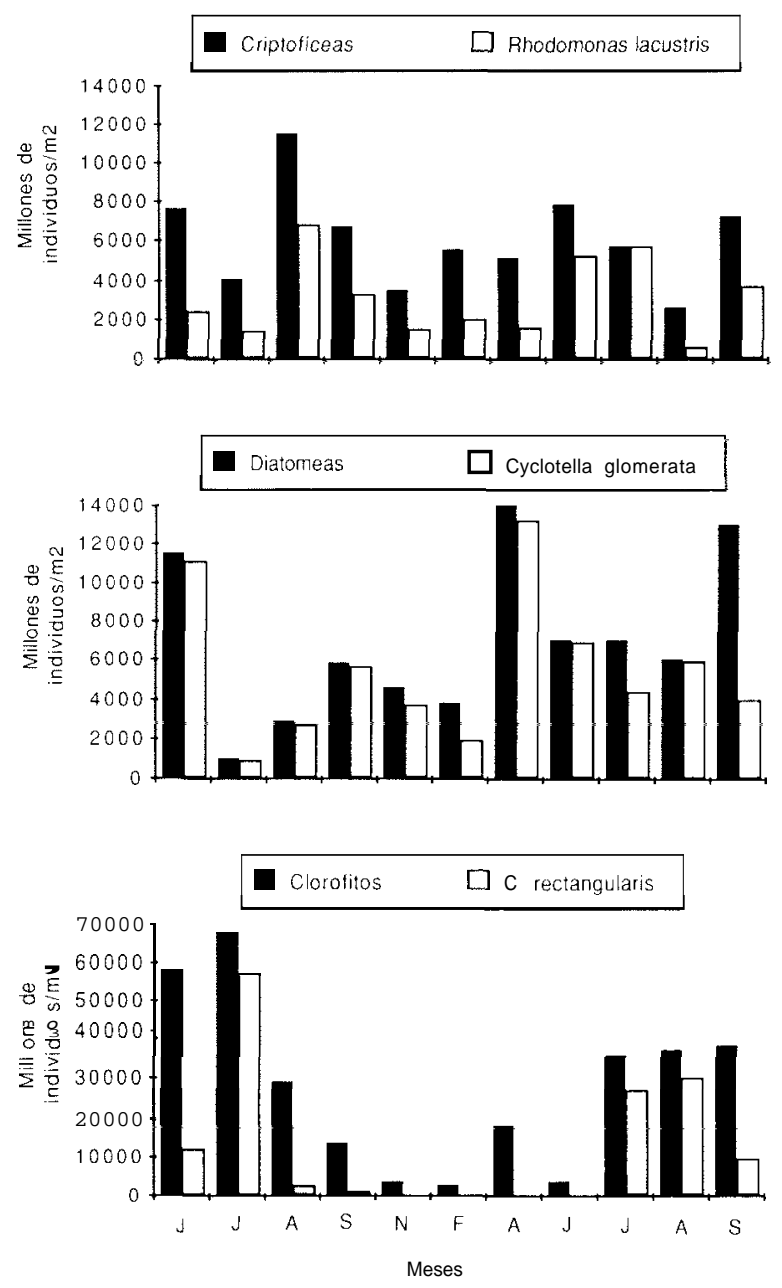

Figura 4. - Variación temporal de los principales grupos algales $\left(\right.$ ind $\left./ \mathrm{m}^{2}\right)$ junto con la de su especie más representativa (inicial del mes de muestreo al pie de su histograma respectivo). Temporal variation of the main algal groups $\left(\mathrm{ind} / \mathrm{m}^{2}\right)$ together with their more representativc specics (initial of the sampling month at the bottom of its respectivc histogram). 
rición más puntual pero también importantes a finales de verano fueron Chfamydomonasacuta, sobre todo en 1987, y Planctonema lauterbornii en 1988. En invierno se produjo una notable disminución en el crecimiento de los clorófitos. La variación anual de las clorofíceas de esta laguna parece, pues, depender en gran medida de un grupo reducido de especies que fluctúan cuantitativamente bastante de unos meses a otros. Además de estas especies hay otras que fluctuan poco a lo largo del año, encontrándose en la laguna de forma más o menos continua pero que por no alcanzar importantes porcentajes destacan poco.

Las diatomeas presentan mayores abundancias relativas desde principios de otoño hasta finales de primavera, con una disminución en julio y agosto, tanto en 1987 como en 1988, presentando los porcentajes más elevados en primavera (abril y junio). Esta variación a lo largo del tiempo se corresponde con la de la diatomea céntrica Cyclotella glomerata, la cual alcanzó altas densidades de individuos en los meses anteriormente citados. Así, el porcentaje de diatomeas en junio de 1988 fue de 32,67 , y sólo el de $C$. glomerata ya fue de 32,39 , es decir, prácticamente el $100 \%$ del número total de diatomeas correspondió a esta especie. En cambio, a principios de otoño hay una mayor proporción de diatomeas pennadas, especialmente en el de 1988, en que se observó un notable crecimiento de especies de Nitzschia.

Otro grupo importante es el de las criptofíceas, el cual, a pesar de estar representado sólo por cuatro especies, presentó importantes poblaciones permanentes. Cryptomonas obovata y Cryptomonas phaseolus se localizan preferentemente en las capas de la oxiclina, donde forman densas poblaciones bastante estables, sin embargo, al no aparecer en las otras profundidades, su representación en los totales por columna de agua es pequeña. De todas formas, en noviembre y febrero, cuando baja la densidad del fitoplancton, adquieren proporciones importantes, incluso cuando se considera toda la columna de agua. Las otras dos especies, Rhodomonas lacustris y Cryptomonas erosa, presentaron abundancias relativas mayores por estar menos localizadas en el perfil vertical. Rhodomonas lacustris fue la más abundante y también la más fluctuante, presentando picos de crecimiento en verano.
Los dinoflagelados presentan un gran crecimiento en invierno-principios de primavera, y muestran abundancias relativas bajas en los meses de verano debido a la proliferación de los clorófitos en dichos meses. En febrero fue Gymnodinium varians el dinoflagelado más abundante $(6,7 \%)$, seguido de Peridinium inconspicuum $(5,1 \%)$, aunque esta última especie adquirió gran desarrollo en el mes de abril, durante el cual consiguió el máximo en abundancia absoluta del grupo de todo el período.

Las crisofíceas constituyen un grupo poco representado cuantitativamente, con tendencia a localizarse en verano en la oxiclina, especialmente en el año 1987, año en que ésta fue más estable. En primavera presentaron también un desarrollo muy marcado, situándose a profundidades más superficiales. Las especies responsables de este aumento en abril fueron Chrysolykos planctonicus (10\%), seguida de Chromulina sp. y Kephyrion sp., ambas con un $1 \%$.

Las cianofíceas filamentosas fueron poco importantes, sólo Anabaena sp. fue ligeramente más abundante pero no alcanzó nunca ni el $1 \%$ del fitoplancton total.

Las englenofícias constituyen el grupo que presenta los porcentajes más bajos y también más constantes a lo largo del tiempo, ya que se localizan en la oxiclina y aunque alcanzan densidades altas lo hacen en un pequeño intervalo de profundidades. Astasia curvuta y Astasia cf. oblonga fueron las más abundantes (con densidades en algunos meses superiores a los $500 \mathrm{ind} / \mathrm{ml}$ ), seguidas de Trachelomonas hispida. En noviembre presentaron la mayor abundancia relativa, sin embargo, tal y como se ve en la figura 4 , el máximo en cifras absolutas lo alcanzaron a finales de septiembre de 1988. En abril, debido al descenso sufrido por las especies del género Astasia, se registró el mínimo de todo el período.

En la figura 5 ( A, B y C) se representa la variación estaciona1 por columna de agua de las principales especies del fitoplancton, agrupadas según la semejanza de dicha variación. La distribución temporal en la laguna de la Cruz puede categorizarse según los grupos de especies que se describen a continuación:

1er grupo: especies perennes y constantes: Trachelomonas hispida, Cryptomonas phaseolus, 
Cryptomonus obovata, Cryptomonas erosa, Monoraphidium irregulare, Scerzedesmus quadricauda, Scenedesmus serratus y Euglena acus. Son especies con una variación temporal muy atenuada y en su mayoría localizadas en una estrecha franja del perfil vertical, en la oxiclina, donde las condiciones son más extremas, pero constantes, en el límite de la presencia de luz y oxígeno, pero con altas concentraciones de nutrientes y compuestos orgánicos e inorgánicos derivados de una importante actividad bacteriana. Debido a que probablemente los requerimientos nutritivos deben estar siempre en exceso, las poblaciones, que están adaptadas a dicho ambiente extremo, pueden mantenerse sin grandes fluctuaciones, sólo limitadas por la luz.

2." grupo: especies perennes con máximos en primavera y máximos localizados a más profundidad en verano: Cyclotella glomerata, Peridinium inconspicuum y Pedinomonas minor. Las dos primeras presentan el mayor número de individuos en primavera. $C$. glomeruta es la segunda alga más abundante en el mes de abril, con el $27 \%$ del fitoplancton total, detrás de Pedinomonas minor. P. inconspicuum fue la cuarta en orden de abundancia, con una representación del $8 \%$ (tabla 2). Estas especies salen beneficiadas en períodos con riqueza de nutrientes y ligera turbulencia de las aguas. Forman máximos en el mixolimnion cuando empieza a formarse la termoclina en primavera y también en verano pero localizados a mayor profundidad, en la parte inferior del meta-hipolimnion, justo por encima de la oxiclina (fig. 2).

3er grupo: especies perennes con máximo en verano: Monoraphidium minutum y Rhodomonas lacustris. M. minutum presento característicamente esta distribución, con un máximo en julio-agosto de ambos años. R. lacustris también presentó esta distribución pero con ligeros cambios de un año a otro ya que en 1987 alcanzó su mayor desarrollo en agosto, mientras que en 1988 lo hizo en junio y julio.

4." grupo: especies estivales: este grupo incluye a bastantes especies, pero las que presentan más claramente esta distribución son las siguientes: Crucigenia rectangularis, Scenedesmus linearis, Cosmarium punctulatum, Pseudanabaena limnetica, Pediastrum boryanum, Anabaena sp., Peridinium volzii, Spirulina major y Ceratium hirundinella. Todas ellas presentaron crecimiento desde finales de la primavera hasta el mes de septiembre o principios de octubre. Se trata, pues, de especies, algunas de ellas de tamano relativamente grande, que requieren altas temperaturas y poca turbulencia en el agua para desarrollarse. Éstas son típicas de esa época del año ya que, a medida que avanza la sucesión, las especies de pequeño tamaño y alta tasa de reproducción van siendo sustituidas por otras de mayor tamano y períodos de generación más largos. Este es el caso de Ceratium hirundinella, Peridinium volzii, y las especies del género Cosmarium entre otras. También es el caso de las especies de clorofíceas que forman cenobio-como Crucigeniu rectangularis, Scenedesmus linearis o consorcios como Pediasrrum boryanum, dando lugar a formas grandes con gran acúmulo de mucílago, característico de épocas con concentraciones de nitrógeno y fósforo bajas. Otro grupo estival lo formarían las cianofíceas, las cuales ven favorecido su desarrollo en esta época de escasez de nitrógeno, a pesar de representar en esta laguna una parte muy pequeña del fitoplancton total; es el caso de Pseudanabuena limnetica, Anahaena sp., y Spirulina mujor.

5." grupo: especies otoñales-primaverales e invernales: Chrysolykos planctonicus, Kephyrion sp., Tetraedron minimum, Diceras ollula, Peridinium palatinum y Gymnodinium varians. C. pluncronicus presentó dos máximos, uno en septiembre de 1987 y otro en abril de 1988, disminuyendo en cantidad en noviembre. Kephyriorz $s p$. también presentó dos máximos, el primero en noviembre de 1987 y el segundo en abril de 1988, con una disminución en febrero. Estas dos crisofíceas permanecen en la laguna durante todo el invierno. Diceras ollula, en cambio, sólo se observó desde abril hasta finales de septiembre de 1988 , siendo muy escasa de junio a agosto. T. minimum, $P$. palatinum y Gymnodinium varians presentaron distribuciones típicamente invernales.

En la laguna de la Cruz, el período invernal-primaveral, época en la que las aguas se encuentran mezcladas, se caracteriza por una disminución en el número de individuos en la mayoría de las especies y por la proliferación en especial de las crisofíceas (C. planctonicus, Kephyrion sp.), que aunque no se encuentren en grandes cantidades sí permiten observar que presentan una clara preferencia por los períodos de bajas temperaturas y 
de turbulencia. Estas especies se mantienen hasta finales de primavera pero van siendo sustituidas poco a poco por Cyclotella glomerata, diatomea céntrica de pequeño tamaño que :e favorecido su crecimiento bajo estas condiciones de movimientos y mezcla del agua, y por la clorofícea P. minor, la cual, debido también a su pequeño tamaño alcanza grandes cantidades de individuos en poco tiempo, volviendo a disminuir rápidamente al mes siguiente. El dinoflagelado P. inconspicuum también alcanzó su máximo desarrollo en primavera, en abril concretamente, siendo la cuarta especie más abundante.

Al empezar la estratificación de la laguna, empiezan a adquirir importante desarrollo las especies estivales. En julio la composición fitoplanctónica cambia drásticamente, con una clara dominancia de Crucigenia rectangularis sobre el resto, que se cambia a finales de agosto por una dominancia de Pedinomonas minor, que se mantiene hasta finales de septiembre. La variación anual en el número de individuos por $\mathrm{m}^{2}$ de Crucigenia rectangularis y de Pedinomonas minor, pone de manifiesto la exclusión estacional entre ambas. es decir, sus máximos nunca coinciden en el mismo período sino que se suceden de forma que cuando una alcanza grandes cantidades de individuos, la otra disminuye.

Un comportamiento similar parece que se da entre distintas especies de Peridinium, las cuales tienden a aumentar su población en distintas épocas del año, de forma que Peridinium palatinum es el dinoflagelado más abundante en invierno, Peridinium irzconspicuum presenta su máximo en primavera y Peridinium volzii, especie de mayor tamaño. sólo crece durante los meses de verano.

A finales de septiembre de 1988 hubo una importante proliferación de algunas especies de dia-

Figura 5 (A. B y C). - Distribución temporal de las principales especies según las correspondientes escalas, cuya cifra representa millones $\mathrm{dc}$ individuos por m' (para toda la columna de agua). A: Especies permanentes, B: Especies estivales y C: Especies otoño-primaverales e invernales.

Temporal distribution of the main phytoplankton species according to the respective scales. whose figure represents thousands of individuals per $\mathbf{m}^{2}$ (for the whole water column). A Permanent spccies. B: Suinmer species and C: autumn-spring and winter species.

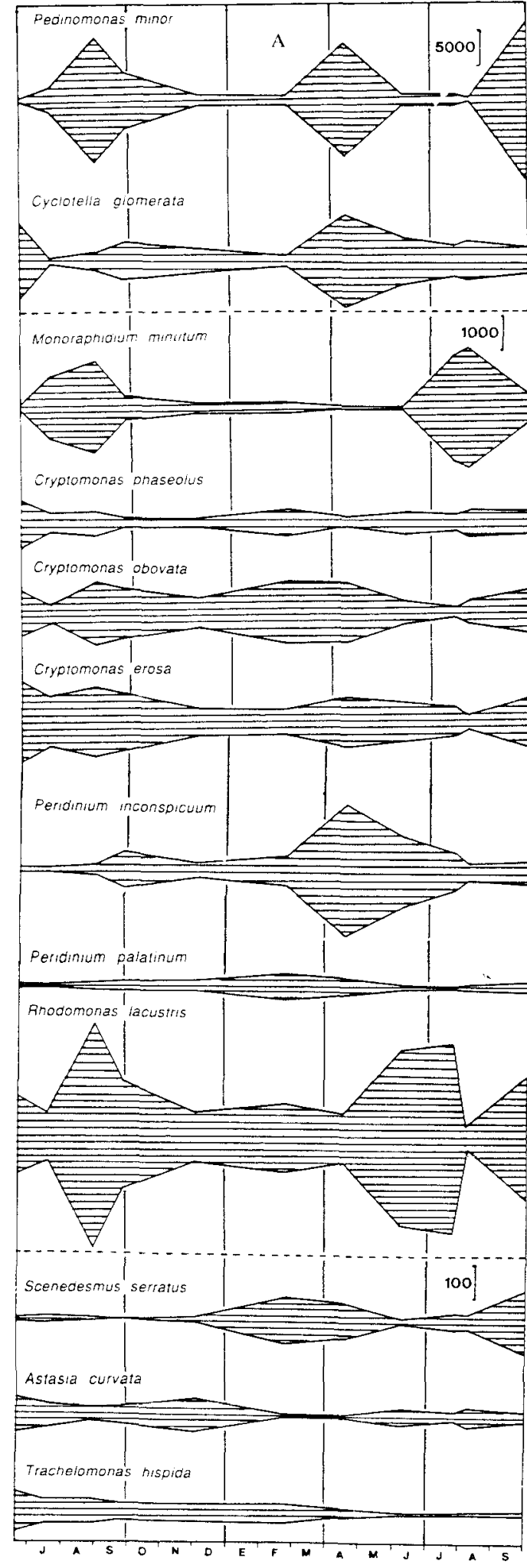




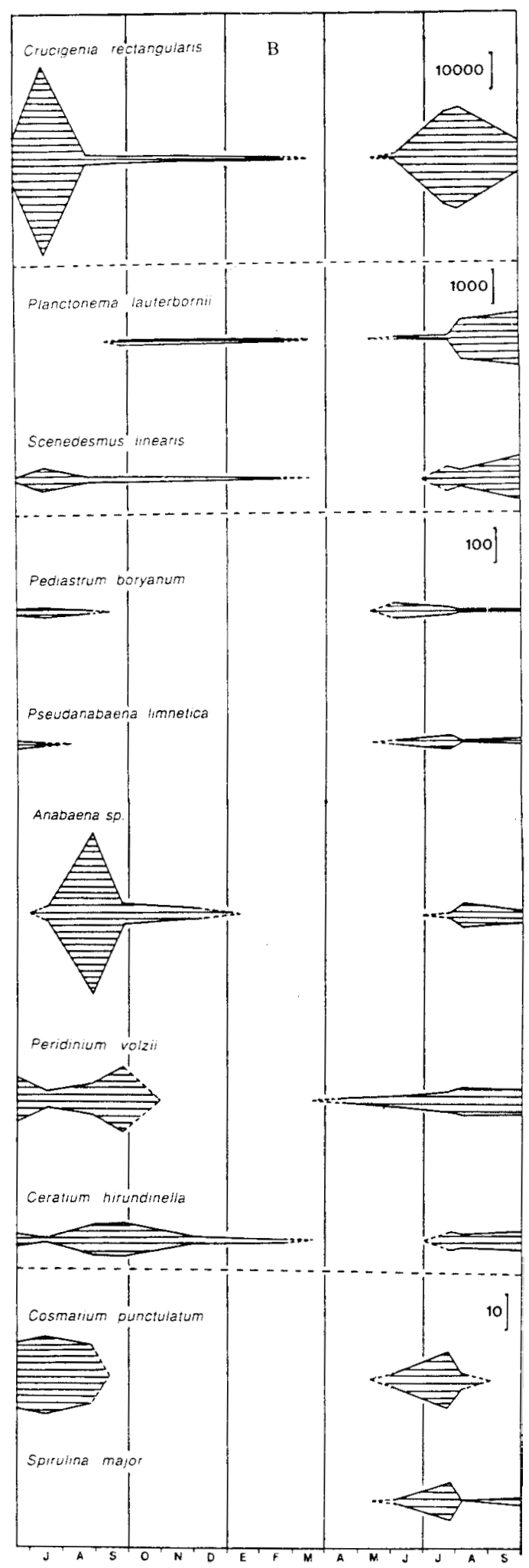

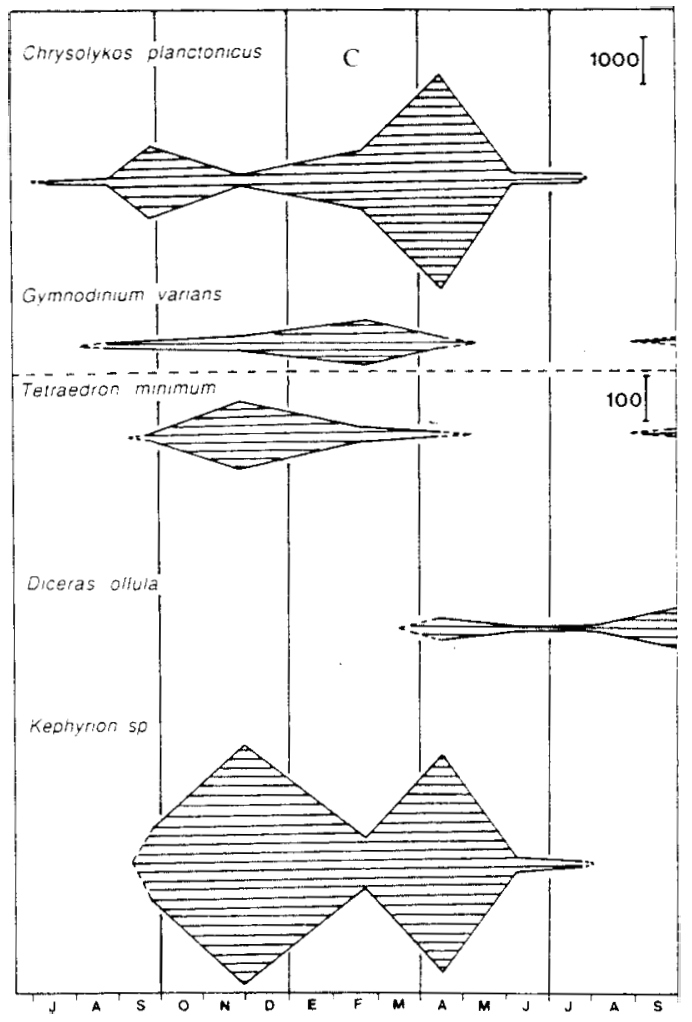

tomeas pennadas, favorecidas, probablemente, por las primeras mezclas verticales entre las capas de agua como consecuencia de que la temperatura ya empezaba a disminuir. Estas diatomeas fueron Nitzschia sp. y Nitzschia palea var. debilis que no se han incluido en ningún grupo debido a que sólo aparecieron ese mes.

Se observan también algunas diferencias entre un ano y otro. El ano 1988 presentó una producción primaria más alta respecto de la de 1987, lo cual se deduce de la gráfica de distribución de la concentración de oxígeno (fig. 1). La oxiclina a su vez se formó más superficialmente en 1988 (extinción de $\mathrm{O}_{2}$ en verano entorno a los $12 \mathrm{~m}$ ) que en 1987 (extinción de $\mathrm{O}_{2}$ en verano a los 15 m). En 1988 se favoreció el crecimiento de la mayoría de las especies, en particular Cyclotella glomerata, Scenedesmus serratus, Planctonema lauterbornii, Spirulina major y Diceras ollula, que presentaron números mucho más bajos en 1987. En cambio, especies como Ceratium hirundinella y Peridinium volzii tuvieron menos crecimiento. 
Tabla 2. - Proporción relativa (\% respecto del total de individuos por colunina de agua) de las 6 especies más importantes en cada día de muestreo. Se indica también el correspondiente valor de la diversidad por columna de agua.

Relative proportion ( $\%$ in respect to he total number of individuals per water column) of the 6 most importani species in each sampling date. The corresponding water column divcrsity value is also indicated.

\begin{tabular}{|c|c|c|}
\hline Fecha & Especies & bits/individuo \\
\hline $17 / \mathrm{VI} / 87$ & $\begin{array}{l}\text { Crucigenia rectangularis } 28.96 \% \text {. Cyclotella glomerata } 26.91 \% \text {. Amoehohucier ap. } 7.41 \% . \text { Crytomonas } \\
\text { erosa } 6.13 \% \text {. Rhodomonas lacustris } 5.73 \% \text {. Pseudoquadrigula sp. } 5.22 \%\end{array}$ & 2.27 \\
\hline $15 / \mathrm{VII} / 87$ & $\begin{array}{l}\text { Crucigenia rectangularis } 73.09 \% \text {. Pedinomonas minor } 5.71 \% \text {, Monoraphidium minutum } 2.48 \% \text {. } \\
\text { Chromulina sp. } 2.07 \% \text {. Cryptomonas erosa } 2.05 \% \text {. Rhodomonas lacustris } 1.89 \%\end{array}$ & 1.91 \\
\hline $27 / \mathrm{VIII} / 87$ & $\begin{array}{l}\text { Pedinomonas minor } 37.85 \% \text {. Rhodomonas lacustris } 13.792 \text {. Chlamydomonas acuta } 5.90 \% \text {, Crucigenia } \\
\text { rectangularis } 5.82 \% \text {. Monoraphidium mmutum } 5.61 \% \text {. Cyclotella glomerata } 5.54 \%\end{array}$ & 2,85 \\
\hline $23 / \mathrm{IX} / 87$ & $\begin{array}{l}\text { Pedinomonas minor } 27.21 \% \text {. Cyclotella glomerata } 18.29 \% \text {, Rhodomonas lacustris } 10,64 \% \text {, Cryptomonas } \\
\text { erosa } 5.54 \% \text {. Chrysolykos planctonicus } 5.20 \% \text {. Cryptomonas obovata } 4,83 \%\end{array}$ & 2,92 \\
\hline $29 / \mathrm{XI} / 87$ & $\begin{array}{l}\text { Cyclotella glomerata } 25.83 \% \text {. Pedinomonas minor } 11.60 \% \text {, Rhodomonas lacustris } 10.49 \% \text {, Cryptomonas } \\
\text { obovata } 6.09 \% \text {. Cryptomonas erosa } 5.79 \% \text {. Cyclotella kützingiana } 4.92 \%\end{array}$ & 3.32 \\
\hline $20 / 1 \mathrm{I} / 88$ & $\begin{array}{l}\text { Rhodomonus lacustris } 12,29 \% \text {. Cryptomonas obovata } 11,34 \% \text {, Cyclotella glomerata } 11,30 \% \text {, Cyclotella } \\
\text { kützingiana } 10,98 \% \text {, Pedinomonas minor } 8.82 \% \text {. Chrysolykos planctonicus } 7.48 \%\end{array}$ & 3,05 \\
\hline $15 / \mathrm{IV} / 88$ & $\begin{array}{l}\text { Pedinomonas minor } 35,39 \% \text {, Cyclotella glomerata } 27,39 \% \text {, Chrysolykos planctonicus } 10,16 \% \text {. Peridinium } \\
\text { inconspicuum } 8.17 \% \text {. Cryptomonas ohovara } 3.75 \% \text {. Rhodomonas lacustris } 3.28 \%\end{array}$ & 2.61 \\
\hline $5 / \mathrm{VI} / 88$ & $\begin{array}{l}\text { Cyclotella glomerata } 32.34 \% \text {. Rhodornonas lacustris } 24.67 \% \text {. Peridinium inconspicuum } 9,81 \% \text {, } \\
\text { Pedinomonas rninor } 8.63 \% \text {. Cryptomonas erosa } 5,59 \% \text {. Cryptomonas obovata } 3,255 \text { : }\end{array}$ & 2.72 \\
\hline $21-27 /$ III/88 & $\begin{array}{l}\text { Crucigenia rectangularis } 55.27 \% \text {. Rhodornonus lacustris } 11,43 \% \text {, Cyclotella glomerata } 8,61 \% \text {, } \\
\text { Monoraphidium minutum } 6,40 \% \text {, Chlorella sp. } 2,84 \% \text {. Peridinium iriconspicuum } 2,27 \%\end{array}$ & 3,32 \\
\hline $5 / \mathrm{VIII} / 88$ & $\begin{array}{l}\text { Crucigenia rectangularis } 62,82 \% \text {. Cyclotella glomerata } 12,36 \% \text {, Monoraphidium miriururn } 6,40 \% \text {, } \\
\text { Planctonema lauterbornii } 2.33 \% \text {. Cryptomonas phaseolus } 1.65 \% \text {, Cryptomonas ohovara } 1,49 \%\end{array}$ & 2.00 \\
\hline $30 / / \times / 88$ & $\begin{array}{l}\text { Pedinomonas minor } 38.91 \% \text {. Crucigenia rectangularis } 15,64 \% \text {, Navicula cf. cryptocephala } 9.36 \% \text {, } \\
\text { Cyclotella glomerata } 6.61 \% \text {, Rhodomonas lacustris } 6 . ! 1 \% \text {. Cryptomonus erosa } 2.63 \%\end{array}$ & 2.72 \\
\hline
\end{tabular}

\section{Diversidad}

Las diversidades calculadas con los números de individuos integrados para la columna de agua fraccionada en epilimnion, metalimnion y oxiclina, aparecen representadas junto con la diversidad media de todo el período estudiado en la figura 6.

El epilimnion fue el estrato con menor diversidad durante 1987, no ocurriendo lo mismo en 1988. Así. a finales de septiembre de 1988, alcanzó una diversidad muy alta ( 3,3 bits), mientras que en el metalimnion fue baja (1,8 bits). Esto se debió al elevado porcentaje durante dicho mes de la clorofícea Pedinomonas minor en el metalimnion (72\%), frente al $2 \%$ que presentó en el epilimnion. Por tanto, y a pesar de haber mayor número de especies en el metalimnion (43 frente a las 38 del epilimnion), éste presentó una diversidad mucho más baja. Algo similar ocurrió en el mes anterior, agosto, pero esta vez con Crucigenia rectangularis, representando el $82 \%$ del fitoplancton total del metalimnion.

La diversidad del metalimnion en 1987 es más o menos paralela a la del epilimnion, aunque con valores más altos, presentando ambas un importante descenso en julio como consecuencia del predominio de C. rectangularis en estos estratos, 


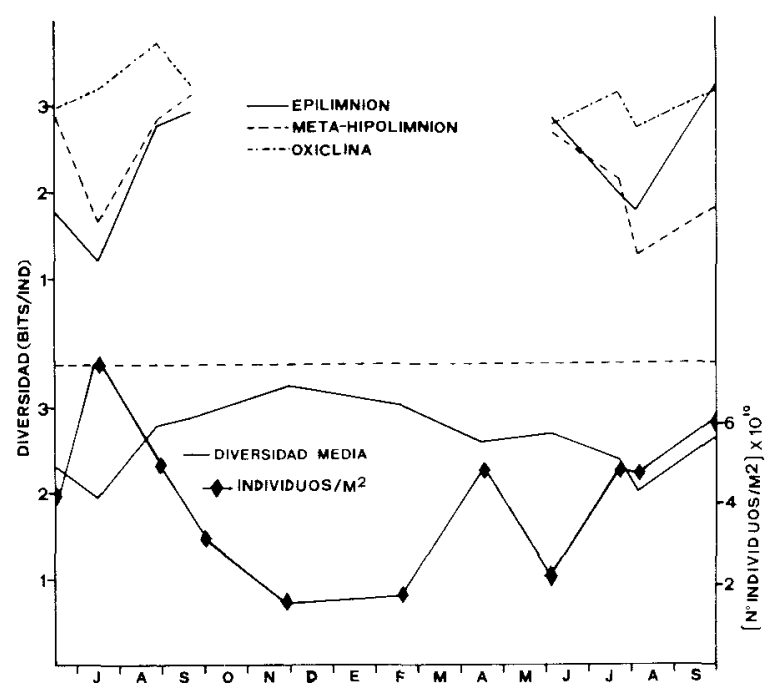

Figura 6. - Comparación de la diversidad media con el número total de individuos $/ \mathrm{m}^{2}$ para toda la columna de agua. En la mitad superior se representa la diversidad de las distintas fracciones de la columna de agua durante los períodos de estratificación.

Comparison between mean diversity and the total number of individuals $/ \mathrm{m}^{2}$ for the whole water column. In the upper half, the diversity for the diffcrent fractions of the water column (epi, metalimnion and oxyclinc) during the stratification periods.

no viéndose afectada la oxiclina debido a que esta especie presentó menor densidad a dichas profundidades.

La oxiclina presentó siempre, los valores de diversidad más altos y menos fluctuantes, debido a que es la zona más estable y en sus marcados gradientes fisicoquímicos pueden establecerse poblaciones estratificadas de diversos organismos.

La diversidad media (media de las diversidades de las distintas profundidades), osciló entre 1,91 y 3,32 bits durante el período estudiado. El ciclo de la diversidad en esta laguna es como sigue: la diversidad es baja en primavera y baja más aún hasta mediados de verano debido a un «bloom»o crecimiento explosivo de algunas clorofíceas ( Crucigenia rectanguluris sobre todo), que favorece el fenómeno de precipitación de calcita-aragonito durante la última semana de julio. Esto puede ocasionar además una disminución del número de especies, por ejemplo en la tabla 3 se puede ver la disminución de especies en el muestreo del 5 de agosto de 1988, que se efectuó justo después de dicho fenómeno. Luego, la diversidad se incrementa desde finales de verano hasta el otoño, produciéndose entonces el máximo. En esta época se observó un aumento tanto en la diversidad como del número de especies, sobre todo de diatomeas pennadas y clorofíceas. Además, especies de dinoflagelados y crisofitos que estaban poco representados anteriormente adquirieron mayor representación. Todo ello, unido a la disminución de la densidad de las especies dominantes en verano. llevó a un aumento de la diversidad, especialmente en las zonas superficiales (mixolimnion). En invierno la diversidad bajó ligeramente para decrecer mucho más marcadamentc en primavera y mediados de verano, tal como se acaba de comentar.

Por esto se da la paradoja de que los períodos de estratificación térmica presentan diversidades bajas, aunque el número de especies fue mayor que en los períodos de mezcla (tabla 3), debido al claro dominio de la especie más abundante. bien C. rectangularis o bien $\mathrm{P}$. minor. La diversidad está inversamente correlacionada con la densidad total de células, relación que no es necesaria, sino una consecuencia de la transitoriedad y dinamismo de las poblaciones muy densas que en esta laguna tienen lugar en primavera y sobre todo en verano.

\section{Grupos de asociación de especies}

Para tipificar el fitoplancton de la laguna de la Cruz se ha realizado un análisis de agrupamiento a partir de la matriz de correlación entre las 99 especies más importantes. Los resultados de este

Tabla 3. - Número de especies de cada grupo encontrado en los distintos días de muestre«.

Numbcr of species of each group identified in cach sampling date.

\begin{tabular}{|c|c|c|c|c|c|c|c|c|c|c|c|}
\hline & \multicolumn{5}{|c|}{1987} & \multicolumn{6}{|c|}{1988} \\
\hline & $J$ & $J$ & $A$ & $S$ & $N$ & $F$ & $A$ & $J$ & $J$ & $A$ & $s$ \\
\hline Dinoflagelados & 10 & 10 & 10 & 7 & 6 & 6 & 6 & 6 & 8 & 8 & 8 \\
\hline Criptofíceas & 4 & 4 & 4 & 4 & 4 & 4 & 4 & 4 & 4 & 4 & 4 \\
\hline Diatomcas & 6 & 5 & 8 & 8 & 13 & 6 & 5 & 5 & 9 & 4 & 9 \\
\hline Crisoficeas & 4 & 3 & 3 & 5 & 3 & 3 & 5 & 5 & 4 & 3 & 2 \\
\hline Euglenoficeas & 3 & 6 & 6 & 4 & 4 & 4 & 5 & 5 & 4 & 4 & 5 \\
\hline Cianofíceas & 4 & 4 & 3 & 8 & 2 & 4 & 3 & 7 & 7 & 4 & 9 \\
\hline Clorofíceas & 22 & 21 & 17 & 25 & 16 & 18 & 16 & 24 & 29 & 22 & 29 \\
\hline Total especies & 53 & 53 & 51 & 61 & 48 & 45 & 44 & 56 & 65 & 49 & 66 \\
\hline
\end{tabular}




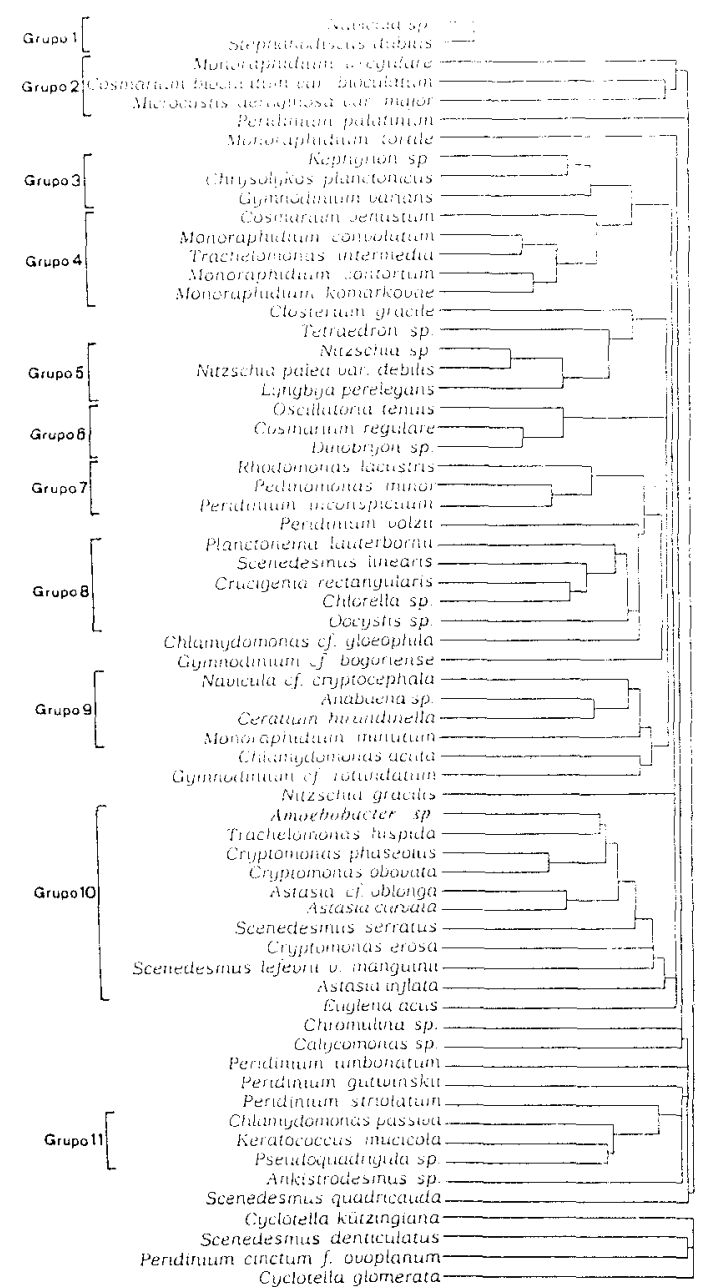

Figura 7. - Dendrograma de afinidad resultante del análisis de agrupamiento efectuado con la matriz de correlación entre las 99 especies de la tabla 1 . Las especies que quedaban a los extremos presentando correlaciones inferiores a 0.2 han sido excluidas.

Dendrogram from the cluster analysis using the correlation matrix betwecn the 99 species in table 1 . Species which came at the cdges and had correlations helow 0.2 have been exeluded.

análisis se presentan en el dendograma de la figura 7. Las correlaciones altas indican que las especies aparecen simultáneamente, tanto temporal como espacialmente. Aquellas especies que aparecen solamente en uno o pocos meses suelen presentar correlaciones altas con las especies de esas mismas muestras. Igual ocurre con aquellas especies que aparecen esporádicamente, por esta ra- zón el análisis «clusters» nos da una serie de grupos poco significativos formados por estas especies de aparición puntual. A continuación se describen los diferentes grupos, los principales en primer lugar y numerados según su ordenación en el dendograma (figura 7).

Grupo 3: Especies invernales. - Este grupo está formado por tres especies, Chrysolykos planctonicus, Kephyriorz sp. y Gymnodinium vurians, las cuales se caracterizan por estar presentes en la laguna durante todo el invierno, aunque sus máximos los presenten en distintos meses (Kephyrion $s p$. en noviembre, $G$. vurians en febrero y $\mathrm{C}$. planctonicus en abril).

Grupo 7: Especies con máximos profundos en verano, que aparecen más superficialmente en primavera. - Este grupo lo forman tres especies que fueron muy frecuentes en la laguna y que presentaron una distribución vertical muy similar. Son las siguientes: Rhodomonas lucustris, Pedinomonas minor y Peridinium inconspicuum.

Grupo 8: Especies estivules que aparecen en gran parte de la columna de agua. - Está formado por Scenedesmus linearis, Crucigenia rectangularis, Chlorella sp., Oocystis sp. y con menor afinidad por ser abundante en sólo uno de los dos años estudiados, Planctonema lauterbornii. Chlorella sp. y Oocystis sp. presentan una distribución más constante a lo largo del año, aunque es en verano cuando presentan mayor desarrollo.

Grupo 9: Especies del epilimnion de verano. Este grupo corresponde a las especies que se localizan siempre en las capas de agua superficiales, sobre todo en los meses en los que la laguna se encuentra estratificada. Estas especies son: Anabaena sp., Ceratium hirundinella, Monoruphidium minutum y Navicula $c f$. cryptocephala.

Grupo 10: Especies de la oxiclina.- Está constituido por las especies que siempre aparecen en las capas de agua más profundas, en la interfase óxico-anóxica: Cryptomonas obovata, C. phaseolus, Astasia curvata, Astasiu cf. oblonga, Trachelomonas hispida, Scenedesmus serratus, Cryptomonas erosu, Astasia inflata y Scenedesmus lefevrii $v$. munguinii. Entre ellas figura también la bacteria fotosintética Amoebobacter, que forma agregados y se ha incluido en el análisis (con contajes del número de agregados) como indicadora de presencia exclusiva en la parte baja de la oxiclina. 
Los otros seis grupos que se van a comentar a continuación están formados por especies que presentan altas correlaciones entre ellas debido a que aparecicron en momentos y puntos muy concretos, no siendo por cllo del todo significativos. Son los siguientes:

Grupo 11: Especies que se encuentran en toda la columna de agua y principalmente en los meses de verano.- Son las siguientes: Pseudoquadrigula sp., Chlamydomonas passiva y Keratococcus mucicola.

Grupo 1: Este grupo lo forman Stephanodiscus dubius y Navicula sp., sólo aparecieron en las muestras correspondientes a septiembre de 1987.

Grupo 2: Especies de la oxiclina-Se encuentran en un grupo aparte del 10 debido a que éstas aparecieron en muchas menos ocasiones, coincidiendo en los mismos meses y a las mismas profundidades. Son: Microcystis aeruginosa vur. major, Cosmarium bioculutum var. bioculatum y Monoraphidium irregulare.

Grupo 4: Especies presentes sólo u finales de verano-principios de otoño. - Estas especies son: Trachelomonas intermedia, Monoraphidium komurkovae, Monoraphidium contortum y Monoraphidium convolutum y Cosmarium venustum.

Grupo 5. - En este grupo se encuentran Nitzschia palea var. debilis, Nitzschia sp. y Lyngbya perelegans. Las dos primeras presentan una alta correlación debido a que sólo aparecieron en septiembre de 1988, Lyngbya perelegans también alcanzó uno de sus mayores crecimientos dicho mes, aunque estuvo presente en otros.

Grupo 6: Son: Oscillatoria tenuis, Cosmarium regulare y Dinobryon sp., las cuales aparecieron en contadas ocasiones, coincidiendo las tres en septiembre de 1987.

\section{DISCUSIÓN}

El fitoplancton de la laguna de la Cruz es el característico de los lagos cársticos de la Península Ibérica. De la comparación de nuestros resultados con los estudios existentes de otros lagos cársticos como Banyoles (Planas, 1973), Vilá (García, 1973), Montcortés (CAmps et al., 1976, Modamio et al., 1988) y Estanya (Avila et al., 1984), se observan claras similitudes, existiendo en todos ellos poblaciones importantes de Cyclotella durante todo el ano, situándose al inicio de la termoclina, y poblaciones metalimnéticas más profundas de Peridinium de varias especies que se suceden en el tiempo. Igualmente, en algunos de ellos se dan crecimientos explosivos de clorofíceas.

En aquellos que presentan una marcada estratificación con condiciones anóxicas durante largos períodos de tiempo (Vilá, García, 1973; Sisó, PEDRÓS-Aı.ó et al., 1987), se confirma la presencia característica en la oxiclina de algunas de las especies encontradas por nosotros en esta zona, especialmente Cryptomonas y euglenales que en algunos de estos lagos (Montcortés, Modamı et al. 1988; Arcas, Fınlay et al. 1991) van acompañadas por especies de Oscillatoria.

En la laguna de la Cruz el número de especies mayoritarias es en realidad pequeño. De las 133 especies identificadas, sólo 13 especies se presentaron en más del $50 \%$ de las muestras y 37 presentaban una frecuencia relativa mayor del $1 \%$ del total de individuos del fitoplancton contabilizado.

Es de gran interés señalar que las características de meromixis permanente de este lago permiten confirmar la adaptación de algunas especies a condiciones de intensidades de luz muy bajas (menos de 1-2 $\mu \mathrm{E} \times \mathrm{m}^{-2} \times$ seg '). Dichas especies se encontraban preferentemente y algunas exclusivamente a profundidades con estas intensidades de luz tan bajas y algunas de ellas presentaban densidades de población relativamente significativas por debajo de la profundidad de extinción del oxígeno. Esto significa que estas especies deben poseer además mecanismos distintos de la fotosíntesis para sobrevivir, como metabolismo heterotrófico. Las especies más características adaptadas a estas condiciones en la laguna estudiada son las euglenales de los géneros Astasia, Euglena y Trachelomonas, y las especies de Cryptomonas, con algunas de Scenedesmus, que se encuentran coexistiendo con las poblaciones de bacterias fotosintéticas, principalmente Amoebobacter, según se desprende del análisis estadístico.

El fitoplancton de la laguna de la Cruz está constituido por una serie de comunidades bien diferenciadas, especialmente la comunidad de la oxiclina, característicamente separada de las demás. Las comunidades del mixolimnion se separan fundamentalmente por la época del año. 
En el mixolimnion la sucesión estacional sigue, en líneas generales las etapas características definidas en la literatura para los lagos templados: una primera etapa en primavera con predominio de clorofíceas y diatomeas de pequeño tamaño, $(P e-$ dinomonas minor y Cyclotella glomerata); una segunda etapa hacia principios de junio con proliferación de criptofíceas (Cryptomonas erosa y Rhodomonas lucustris) y en la que las diatomeas siguen siendo importantes todavía; una tercera etapa durante el verano con claro predominio de las clorofíceas, primero con desarrollos masivos de C. rectunguluris que favorecen la precipitación de calcita y aragonito a finales del mes de julio, cambiando el color del agua de verde azulado a blanco lechoso, seguidos luego por crecimientos importantes de otras especies, principalmente Pedinomonas minor. Finalmente, la cuarta etapa, desde finales de verano hasta el invierno, se caracterizó por la disminución de la abundancia de las clorofíceas y mayor desarrollo de los dinoflagelados (Peridinium pulatinum, Gymnodinium varians, etc.) y de las crisofíceas (Chrysolykos planctonicus, Kephyrion sp., etc.).

Las condiciones de la laguna permiten pues el crecimiento masivo de ciertas clorofíceas, en concreto de Pedinomonas minor en primavera y finales de verano y Crucigenia rectunguluris en verano, especialmente en el año 1988 , verano que sucedió a una primavera muy lluviosa que determinó una menor profundidad de la oxiclina, con la consiguiente elevación de los nutrientes a capas con intensidades mayores de luz.

Por ello, la diversidad muestra una clara relación inversa con la densidad total de células, como es de esperar, presentando marcadas disminuciones durante los crecimientos algales masivos de las clorofíceas que tuvieron lugar en la primavera y verano. La diversidad luego aumenta desde finales de verano hasta el otoño, produciéndose entonces los valores máximos, y decrece ligeramente en invierno.

En Rojo y Miracle (1987) se presenta un estudio sobre la distribución de las poblaciones fitoplanctónicas de la laguna de la Cruz, a partir de muestras tomadas en diferentes fechas desde 1981 a 1985. La comparación entre nuestros resultados de los años 1987-88 con los de los años antes citados pone de manifiesto la coincidencia de las especies mas abundantes, así como también la de sus máximos de abundancia. Tal es el caso de Cyclotella glomerata, la cual presentó también su máximo en el mes de abril en aquel estudio de los años 1981-85, apareciendo también en casi toda la columna de agua, incluso por debajo de la oxiclina. Crucigeniu rectangularis y Monoraphidium minutum fueron muy abundantes también en dichos años y con sus mayores poblaciones en los meses de verano y en el mixolimnion, con un predominio casi exclusivo de C. rectangularis en agosto de 1982.

Euglenofíceas, sobre todo del género Astasia y Euglena y Cryptomonas ( $C$. obovata y $C$. phaseolus) también se localizaron principalmente en la oxiclina. Otra especie que presentó una distribución temporal muy similar a la encontrada ahora es la clorofícea Planctonema lauterbornii, la cual creció también a finales de verano.

La distribución de los dinoflagelados sí fue ligeramente distinta puesto que algunas especies como Peridinium palatinum y $P$. inconspicuum presentaron en 1983 mayores densidades hacia el mes de junio, mientras que en el ciclo ahora estudiado aparecen en épocas más frías, llegando $\mathrm{P}$. pulatinum a presentar su máximo en febrero.

En general se puede decir que las especies son bastante constantes a lo largo del tiempo, y que los principales grupos se distribuyen, en líneas generales, de forma similar.

\section{AGRADECIMIENTOS}

Debemos agradecer la colaboración incondicional de Eduardo Vicente en todas las fases de realización del trabajo sin cuya participación no hubiera sido posible. Damos también las gracias a M.A. Rodrigo, J. Armengol, A. Camacho y L. Ballesteros su ayuda en el trabajo dc campo. Este estudio ha sido subvencionado por el Proyecto de investigación de la C.A.Y.C.I.T. otorgado a M.R.M.

\section{Bibliografía}

Ávila. J., Burrel. A.. A. Domingo, E. Fernandez. J. Go DAlL \& M. Ll.OPART, 1984. Limnología del lago Grande de Estanya (Huesca). Oecologia aquatica, 7: 3-24. 
Camps, J., I. Gonzalyo, J. Guell, P. Lopez, A. Tejero, X. Toldrá, F. Vallespinos \& M. Vicens, 1976. El lago de Montcortés: descripción de un ciclo anual. Oecologia aquatica, 2: 99-110.

Finl.AY, B.J., 1990. Physiological ecology of free-living protozoa. Advances in Microbial Ecology, 11: 1-35.

Finlay, B.J. \& T. FEnCHEL, 1986. Spatial distribution of microaerophilic ciliates in lakes: the interacting roles of oxygen tension blue light and gravity. Perspectives in Microbial Ecology. Slovenian Soc. Microbiol., pp. 343-348. Ljubjana, Yugoslavia.

Finlay, B.J.. K. Clarke, E. Vicente y M.R. Miracle, 1991. Anaerobic ciliates frorn a sulphide rich-solution lake in Spain. Emop. J. Protitol., 27: 148-159.

Florek, K., J. Lukaszewicz, J. Perkal. H. Steinhaus \& S. ZUBRZYCKI, 1951 a. Sur la liason et la division des points d'un ensemble fini. Colloquium Math., 2: 282-285.

Florek, K., J. Lukaszewicz, J. Perkal, H. Steinhaus \& S. ZubrZYCKI, 1951 b. Taksonomia Wroclawska. Przegl. An tropol., 17: 193-211.

Garcia, M.O., 1973. Fitoplancton de la Laguna del Vilá (Gerona, España). Oecologia aquatica, 1: 107-155.

Guerrero, R., E. Montesinos, C. Pedrós-Alió, I. Esteve \& J. MAs, 1985. Phototrophic sulfur bacteria in two Spanish lakes: Vertical distribution and limiting factors. Limnol. Oceanogr., 30 (5): 919-931.

Guerrero, R., C. Pedrós-Alió, I. Esteve \& J. Mas, 1987. Cornmunities of phototrophic sulfur bacteria in lakes of the Spanish Mediterranean region. Acta academiae Aboensis, 47 (2): 125-151.

Margalef, R., 1983. Limnología. Omega. Barcelona. $1010 \mathrm{pp}$.
Modamio, X., V. Pérez \& F. Samarra. 1988. Limnologia del lago de Montcortés (ciclo 1978-79) (Pallars Jussá, Lleida). Oecologia aquatica, 9: 9-17.

Moore, J.W., 1981. Seasonal ahundancc of Ceratium hirun dinella (O.F. Müller) Schrank in lakes of different trophy. Arch. Hydrobiol., 92 (4): 535-548.

Morgan, K. \& J. KalfF. 1975. The minter dark survival of an algal flagellate, Cryptomonas erosa (SKUJA). Verh. Internai. Verein. Limnol., 19: 2734-2740.

Pedrós-Alió, C., J.M. Gasol \& R. Guerrero, 1987. On the ecology of a Cryptomonas phaseolus population forming a rnetalimnetic bloom in Lake Cisó, Spain: Annual distribution and loss factors. Limnol. Oceanogr., 32 (2): 285-298.

Planas, D., 1973. Composición, ciclo y productividad del fitoplancton del lago de Banyoles. Oecologia aquatica, 1: 3-106.

Ramon, G. \& G. Moya. 1984. Distribución estacional de Planctonema lauterbornii, (Ulotrichaceae) en dos embalses de aguas mineralizadas (Cúher y Gorg Blau, Mallorca). Limnética, 1: 291-296.

Rojo, C. \& M.R. Miracle. 1987. Poblaciones fitoplanctónicas de la Laguna de la Cruz (Cuenca), una laguna cárstica merorníctica. Act. VI. Simp. Nac. Bot. Cript., Granada (Spain): 119-135.

Rojo, C. \& M.R. MiRACle, 1989. Phytoplankton Fluctuations during an Annual Cycle in the Coastal Lagoon of Cullera (Spain). Int. Revue. ges. Hydrobiol., 74: 179-194.

SNEATH, P., 1957. «The application of computers to taxonomy». Journal of General Microbiology, 17: 201-226.

Streble, H. \& D. Krauter, 1987. Atlas de los Microorganismos de Agua Dulce. Omega. Barcelona. 371 pp.

ViCente, E. \& M.R. MiraCle, 1988. Physicochemical and microbial stratification in a meromictic karstic lake of Spain. Verh. Internat. Verein. Limnol.. 23: 522-529. 